No. 06-17

\title{
International Risk-Taking, Volatility, and Consumption Growth
}

\author{
Maria Giduskova and Borja Larrain
}

\begin{abstract}
We show that countries that take on more international risk are rewarded with higher expected consumption growth. International risk is defined as the beta of a country's consumption growth with world consumption growth. High-beta countries hold more foreign assets, as predicted by the theory. Despite the positive effects of beta, a country's idiosyncratic volatility is negatively correlated with expected consumption growth. Therefore, uninsured shocks affect not only current growth, but also future consumption growth. High-volatility countries have worse net foreign asset positions, suggesting that solvency constraints limit their future growth.
\end{abstract}

JEL Codes: E21, F3, G1, O16, O4

Maria Giduskova is a research associate at the Federal Reserve Bank of Boston. Borja Larrain is an economist at the

Federal Reserve Bank of Boston. Their email addresses are maria.giduskova@bos.frb.org and borja.larrain@bos.frb.org, respectively.

This paper, which may be revised, is available on the web site of the Federal Reserve Bank of Boston at http://www.bos.frb.org/economic/wp/index.htm.

The views expressed in this paper are solely those of the authors and do not reflect official positions of the Federal Reserve Bank of Boston or the Board of Governors of the Federal Reserve System.

This version: November 2006. 
This paper shows that countries that take on more international risk are rewarded with higher expected consumption growth. International risk-taking, which we call a country's beta, is defined as the covariance of national consumption growth with world consumption growth, scaled by the variance of the world. In equilibrium, beta is equal to the fraction of a country's wealth invested in the world market portfolio. Our results show that a onestandard-deviation increase in beta increases average consumption growth by 40 basis points over the following five years. This finding is consistent with models of international risksharing like the one presented by Obstfeld (1994b).

Perfect risk-sharing has been widely rejected by empirical studies. ${ }^{1}$ Most tests deal with one stark implication of perfect risk-sharing: that world risk is the only risk that matters. Beyond measurement error, any fluctuation in consumption unrelated to world consumption is inconsistent with complete markets. The failure of perfect risk-sharing is illustrated by the high correlations of a country's consumption and income, even after controlling for movements in world consumption. ${ }^{2}$ However, these correlations are not informative about the reward for holding world risk, or, in other words, about whether world risk matters at all. Most empirical studies only document that factors other than world risk also matter for consumption growth, but remain silent about the existence of a risk-growth tradeoff. Our tests with beta study this tradeoff directly.

Despite the positive effect of beta, we find that the idiosyncratic part of a country's volatility is detrimental for future consumption growth. If there is perfect risk-sharing, this volatility should not be reflected in consumption, since it is orthogonal to world risk (by definition). However, we show that idiosyncratic shocks are reflected not only in present consumption, but also in future consumption. In other words, the negative effects of imperfect risk-sharing are persistent. These results are analogous to those in Ramey and Ramey

\footnotetext{
${ }^{1}$ See Lewis (1999) for a survey of international risksharing. Lewis (1996) and Obstfeld (1994a) among others document the failure of perfect international risksharing. Cochrane (1991) and Mace (1991) perform tests of perfect risksharing within the U.S.

${ }^{2}$ Fuhrer and Klein (1998) question the interpretation of high correlations with the world as a sign of good risksharing in a model with habit formation.
} 
(1995) regarding the negative relationship between GDP volatility and GDP growth in a cross-section of countries.

By empirically identifying the welfare implications of different risks, this paper highlights the potential benefits of financial integration and financial innovation. Our finding of a premium on world risk confirms the large welfare gains of international financial integration estimated by Athanasoulis and Shiller (2001), Athanasoulis and van Wincoop (2000), Obstfeld (1994b) and others. The fact that this premium exists even without a formal market for "world shares" makes more pressing the recommendation of Athanasoulis and Shiller (2000) concerning the need for such a world market. In addition, our results indicate that insurance mechanisms for some idiosyncratic shocks are still missing and can have long-lasting consequences if created.

Our results are also interesting from the perspective of the empirical growth literature. Beta and idiosyncratic volatility are two powerful predictors of per capita consumption growth in our sample of 74 countries over the last 50 years, particularly at medium-run horizons between 3 and 10 years. These risk measures have forecasting power above and beyond traditional growth determinants such as the ratio of investment to GDP or measures of human capital. After controlling for beta, volatility, and other country characteristics, we still observe conditional convergence, that is, the idea that high initial income forecasts low subsequent growth (Barro (1991)).

One advantage of beta as a growth predictor is that it is not highly correlated with income levels, unlike more traditional variables. The high correlation of other variables introduces multicollinearity problems in cross-country growth regressions (Mankiw (1995)). We show that, although rich countries have slightly higher betas on average when compared with lessdeveloped countries, the spread in betas is much wider in less-developed countries. In other words, having a high beta with the world is not necessarily an indication of high income. In contrast, the effects of volatility and income are harder to disentangle, because volatility clearly decreases with income. 
These findings also complement the results in the literature on risk-taking and development (for example, Acemoglu and Zilibotti (1997), Koren and Tenreyro (2005)). While our paper concentrates on international risk-taking, the focus of this literature is on development and the diversification of the domestic production structure.

Finally, we correlate our measures of risk with direct measures of financial integration from Lane and Milesi-Ferretti (2001). These measures confirm the mechanisms working behind the risk-growth tradeoffs. We show that, as predicted by the theory, a country's beta is positively correlated with the stock of foreign assets as a fraction of GDP accumulated by the country. At the same time, countries with high volatility have lower stocks of foreign assets and similar levels of foreign liabilities. Therefore, their net foreign asset position is more negative. This suggests that highly volatile, and, perhaps for this reason, indebted countries hit solvency constraints that limit their investment and future growth.

The paper is organized as follows. Section 1 derives the positive relationship between international risk-taking and expected consumption growth in a complete-markets model. Section 2 describes the main data sources and measurement issues. Section 3 presents the basic results, plus the examination of other standard determinants of growth across countries. Section 4 digs deeper into the measures of risk by correlating them with economic development and the foreign asset position of a country. Section 5 concludes. The appendix contains robustness checks and supplementary data.

\section{A Model of International Risk-Taking and Consump- tion Growth}

The finance literature has a long tradition of testing and identifying risk-return tradeoffs. The Capital Asset Pricing Model (CAPM), for example, implies that stocks that have a high beta with the market return should yield high average returns. This paper follows that tradition, but it correlates a country's consumption growth, and not asset returns, with a 
measure of risk-taking. Both ideas are related. Higher risk-taking fuels average consumption growth precisely because risky technologies yield higher average returns. Obstfeld (1994b) was the first to apply this fundamental intuition of finance to the study of the benefits of international financial integration. By following the risk-return tradition, this paper highlights the connection between average growth and risk, or equivalently between first and second moments of the growth distribution.

\subsection{Investor Behavior}

This section closely follows Obstfeld (1994b), who sets up a portfolio model of international risk-taking in the style of Merton (1971). There is an infinitely-lived, representative agent in the economy. Lifetime utility is characterized by Duffie-Epstein (1992a,b) preferences:

$$
J_{0}=E_{0}\left(\int_{0}^{\infty} f\left(C_{t}, J_{t}\right) d t\right)
$$

where $f\left(C_{t}, J_{t}\right)$ is a function that aggregates consumption $\left(C_{t}\right)$ and continuation utility $\left(J_{t}\right)$. This function takes the form

$$
f(C, J)=\frac{\delta(1-\gamma) J}{1-1 / \psi}\left[\left(\frac{C}{((1-\gamma) J)^{1 /(1-\gamma)}}\right)^{1-1 / \psi}-1\right] .
$$

In this specification, $\delta$ is the subjective discount rate, $\gamma$ is the coefficient of relative risk aversion, and $\psi$ is the elasticity of intertemporal substitution.

Imagine that at each point in time the representative agent can invest in two assets: a riskless bond $(B)$ and a risky asset $(Y)$. Returns on these assets follow one-dimensional Ito processes:

$$
\begin{aligned}
\frac{d B}{B} & =r d t \\
\frac{d Y}{Y} & =\mu d t+\sigma d z
\end{aligned}
$$


Uncertainty is captured by the term $d z$, which is a standard Brownian motion. If we let $k$ be the percentage of wealth $(W)$ allocated to the risky asset, then the change in wealth during an interval $d t$ is

$$
\begin{aligned}
d W & =(1-k) W \frac{d B}{B}+k W \frac{d Y}{Y}-C d t \\
& =[(1-k) W r+k W \mu-C] d t+k W \sigma d z
\end{aligned}
$$

The optimization problem consists in choosing the paths of consumption and portfolio allocations that maximize (1), subject to the dynamic budget constraint and a given level of initial wealth. Let $J(W)$ denote the maximum level of lifetime utility as a function of wealth, which is the state variable of the problem. The Bellman equation for this problem is then

$$
0=\max _{\{C, k\}}\left\{f(C, J)+J_{w}[(1-k) W r+k W \mu-C]+\frac{J_{w w}}{2} k^{2} W^{2} \sigma^{2}\right\} .
$$

From the first-order conditions of this equation we can express $C$ and $k$ as

$$
\begin{gathered}
C=(1-\gamma) \delta^{\psi} J_{w}^{-\psi} J^{\frac{1-\gamma \psi}{1-\gamma}} \\
k=\frac{-J_{w}}{W J_{w w}}\left(\frac{\mu-r}{\sigma^{2}}\right) .
\end{gathered}
$$

As is typical in the case of isoelastic preferences, we can guess that the value function takes the form $J=(A W)^{1-\gamma} /(1-\gamma)$ for some constant $A .^{3}$ Therefore, the optimal consumption and investment policies are

\footnotetext{
${ }^{3}$ After substituting the guess for the value function into the Bellman equation (5), we obtain that the unknown constant $A$ is equal to

$$
A=\left\{\delta^{-\psi}(1-\gamma)^{\frac{\gamma(1-\psi)}{1-\gamma}} \psi\left[\delta-\left(1-\frac{1}{\psi}\right)\left(r+\frac{(\mu-r)^{2}}{2 \gamma \sigma^{2}}\right)\right]\right\}^{\frac{1}{1-\psi}}
$$
}




$$
\begin{gathered}
\frac{C}{W}=\psi\left[\delta-\left(1-\frac{1}{\psi}\right)\left(r+\frac{(\mu-r)^{2}}{2 \gamma \sigma^{2}}\right)\right] \\
k=\frac{\mu-r}{\gamma \sigma^{2}} .
\end{gathered}
$$

The consumption-wealth ratio and the fraction of wealth invested in the risky asset are both constants. Given (8) and the process for wealth in (4), the dynamics of consumption are

$$
\frac{d C}{C}=g d t+k \sigma d z
$$

where $g$ is the instantaneous expected growth rate of consumption given by

$$
g=\psi(r-\delta)+(1+\psi) \frac{(\mu-r)}{2} k
$$

We write $g$ as a function of the fraction invested in the risky asset in order to emphasize the positive relation between risk-taking and expected consumption growth (conditional on the existence of an equity premium $\mu>r$ ). It is also helpful to define the following measure of comovement of consumption growth and the return on the risky asset:

$$
\beta=\frac{\operatorname{Cov}\left(\frac{d C}{C}, \frac{d Y}{Y}\right)}{\operatorname{Var}\left(\frac{d Y}{Y}\right)} .
$$

From (3) and (10) we get that $\beta=k$. The comovement of consumption and the asset return increases as the investment in the risky asset increases. Following (9), this implies that beta depends crucially on the risk aversion of the representative investor. Beta can be negative if the investor is selling short the risky asset. It can also be larger than 1 if the investor is taking on leverage to increase the investment in the risky asset. From an empirical standpoint, it is important that beta is the regression coefficient of consumption growth on the risky return. 


\subsection{Equilibrium in an Integrated World Economy}

The previous section describes the behavior of a representative investor in a partial equilibrium setting (that is, the interest rate is given exogenously). We now consider the equilibrium in a multicountry economy. ${ }^{4}$

We assume that each country has a representative investor with Duffie-Epstein preferences. However, preference parameters may vary across countries, most importantly the risk aversion coefficient that governs the amount of risk-taking. ${ }^{5}$ We use $\gamma_{j}$ to denote the risk aversion coefficient of the representative investor in country $j(j=1, \ldots, N)$. For simplicity, we assume that the elasticity of intertemporal substitution and the rate of time preference are the same across countries. ${ }^{6}$

Each country owns a risky technology like the one in (3) with expected return $\mu_{j}$, instantaneous variance $\sigma_{j}$, and country shock $d z_{j}$. The $N \times 1$ column vector of expected returns is denoted by $\boldsymbol{\mu}$. The variance-covariance matrix of these country-specific technologies is $\boldsymbol{\Sigma}$, which is assumed to be invertible.

Every country can lend and borrow freely at the world interest rate $r^{*}$. If asset trade is frictionless across country borders, then the demand for risky securities of the representative investor of country $j$ is

$$
\mathbf{k}_{j}=\boldsymbol{\Sigma}^{-1}\left(\boldsymbol{\mu}-r^{*} \mathbf{1}\right) / \gamma_{j},
$$

where 1 is an $N \times 1$ vector of ones. These asset demands imply that all investors hold risky assets in the same proportions. This corresponds to the mutual-fund theorem, first

\footnotetext{
${ }^{4}$ The classic reference for general equilibrium models in continuous time is Cox, Ingersoll, and Ross (1985).

${ }^{5}$ Many papers assume that risk aversion is the same across countries, which effectively shuts down differences in risk-taking. Allowing for heterogeneity in risk aversion does not change the basic implication of complete markets - that the correlation of individual consumption and aggregate consumption should be one. However, if risk aversion varies, the volatility of each country with respect to the world is not one anymore. This heterogeneity in risk aversion can be a source of misspecification in previous empirical studies of consumption risksharing.

${ }^{6}$ As supporting evidence for this assumption, Yogo (2004) reports that the elasticity of intertemporal substitution is small and not significantly different from 0 in eleven developed countries.
} 
noted by Tobin (1958) and then by Merton (1973) in a continuous-time model. The ratio of risky to risk-free investments is decreasing in the risk aversion of each investor, but the relative weights in the portfolio of risky investments remain constant across investors. The vector of weights in the global mutual fund is

$$
\boldsymbol{\theta}=\boldsymbol{\Sigma}^{-1}\left(\boldsymbol{\mu}-r^{*} \mathbf{1}\right) / \mathbf{1}^{\prime} \boldsymbol{\Sigma}^{-1}\left(\boldsymbol{\mu}-r^{*} \mathbf{1}\right)
$$

The weight of each country's risky asset in the global mutual fund is denoted by $\theta_{j}$. The mutual fund theorem allows us to use the formulas from the previous section by defining the expected return and variance of the global mutual fund as $\mu^{*}=\boldsymbol{\theta}^{\prime} \boldsymbol{\mu}$ and $\sigma^{* 2}=\boldsymbol{\theta}^{\prime} \boldsymbol{\Sigma} \boldsymbol{\theta}$.

The market-clearing condition that determines the world interest rate is

$$
\sum_{j=1}^{N} \theta_{j}=1,
$$

or in other words, there is no net borrowing or lending in the aggregate. In equilibrium, some countries are net borrowers and some countries are net lenders, depending on their risk aversion, but long and short positions in the risk-free asset cancel out once we aggregate them. Investors with low risk aversion who want to invest more than 100 percent of their wealth in the global mutual fund will borrow from risk-averse foreigners at the world interest rate. Also note that since all investors hold the same mutual fund, then in equilibrium this has to be the market portfolio, that is, each $\theta_{j}$ equals the total wealth invested in that asset relative to world wealth. ${ }^{7}$

In equilibrium, the expected consumption growth rate of country $j$ is

$$
g_{j}=\psi\left(r^{*}-\delta\right)+(1+\psi) \frac{\left(\mu^{*}-r^{*}\right)}{2} k_{j}^{*}
$$

\footnotetext{
${ }^{7}$ We have not mentioned short-sale constraints in this analysis. It may be the case that global investors want to short some country's risky technology $\left(\theta_{j}<0\right)$, which is not possible in equilibrium. A risky technology under those circumstances will shut down and wealth will be allocated to other assets. We can assume that $M<N$ technologies remain open in equilibrium, in which case all of the analysis above applies by considering that the market portfolio is defined over those $M$ assets. The definitions of $\theta_{j}, \mu^{*}$, and $\sigma^{* 2}$ are analogous.
} 
where $k_{j}^{*}$ is the fraction of wealth that the representative investor of country $j$ puts in the market portfolio. We can define $\beta_{j}^{*}$ as before and obtain the following relationship between expected consumption growth and the market beta of the country

$$
g_{j}=\psi\left(r^{*}-\delta\right)+(1+\psi) \frac{\left(\mu^{*}-r^{*}\right)}{2} \beta_{j}^{*}
$$

Equation (17) is the starting point for our empirical analysis. It implies that in a crosssection of countries, those with higher market betas should have higher consumption growth on average. In this model, the dispersion in betas across countries is explained by different attitudes towards risk. As in Obstfeld (1994b), countries with lower risk aversion take greater advantage of risky technologies with higher returns, which explains their higher consumption growth.

From the market-clearing condition, it follows that world aggregate consumption moves one-to-one with the market portfolio. Therefore, $\beta_{j}^{*}$ can also be understood as a measure of comovement of country $j$ with world aggregate consumption. In the empirical section, we implement the model using this definition.

\section{Data and Measurement}

\subsection{Sources and Requirements}

We rely primarily on data from the Penn World Table 6.1 (PWT) with annual coverage from 1950 to 2000. We limit our sample to countries with the following characteristics: (1) data quality must equal grade $\mathrm{C}$ or above; (2) at least 15 years of continuous data must be available; (3) population must be greater than 2 million (with the exception of Luxembourg and Iceland); and (4) average PPP-adjusted per capita GDP for the country must be greater than $\$ 1,000$. This selection process yields a data set with 74 countries, listed in the appendix. From the PWT we take real per capita consumption calculated as a product of real 
PPP-adjusted per capita GDP (PWT mnemonic rgdpl) and the consumption share (PWT mnemonic kc). For robustness purposes, we also use data on real per capita consumption from 1960 to 2004 from the World Development Indicators (WDI) database. These data are not PPP-adjusted, so we can strip off the effects of price changes on consumption growth.

Following previous literature on cross-country growth differences, we also investigate the forecasting power of fertility, (found in WDI) the investment share of GDP (PWT mnemonic ki), and secondary school enrollment (from Barro and Lee (2001)). The measures of foreign assets and liabilities are taken from Lane and Milesi-Ferretti (2001).

\subsection{Estimation of Beta and Idiosyncratic Volatility}

We define the international risk-taking of country $j$ at time $t$ as the covariance between country $j^{\prime} s$ consumption growth and world consumption growth $\left(\Delta c^{*}\right)$, scaled by the variance of world consumption growth. In other words, international risk is the coefficient $\beta_{j, t}$ in the equation below:

$$
\Delta c_{j, t-\tau}=\alpha_{j, t}+\beta_{j, t} \Delta c_{t-\tau}^{*}+\varepsilon_{j, t-\tau}
$$

where $\tau=0,1, \ldots, T$. Per capita consumption growth is defined as $\Delta c_{t-\tau}=\left(c_{t-\tau} / c_{t-\tau-1}\right)-$ $1{ }^{8}$ World consumption growth is measured as a total-consumption-weighted average of national per capita consumption growth rates. Total consumption equals the product of real per capita consumption and population.

We use a backward-looking window to estimate beta at time $t$ for each country. This is the standard way of computing betas in the finance literature (for example, Fama and MacBeth (1973), Fama and French (1992)). We settle on a 10-year estimation window $(T=9)$ as a result of two opposing forces. On one hand, our purpose is to obtain a time-varying measure of a country's risk-taking position; if we use too long an estimation window, beta varies too

\footnotetext{
${ }^{8}$ We work with simple growth rates, instead of log differences, in order to avoid problems with Jensen's inequality. It follows from the model that the expected log-difference of consumption is $g-\frac{1}{2} k^{2} \sigma^{2}$. Results are very similar if we use log differences.
} 
little. On the other hand, the shorter the estimation period, the more sensitive the beta is to measurement error and outliers. Therefore, some smoothing is necessary to obtain a better estimate of the real beta. In the appendix, we show robustness checks with different estimation windows.

We define the idiosyncratic consumption volatility as the standard deviation of the residuals in equation (18). We denote this volatility by $\sigma_{j, t}^{\varepsilon}$. Since the PWT starts in 1950, our measures of beta and idiosyncratic volatility are available from 1960.

\subsection{Timing For Growth Forecasts}

We look at the power of beta and idiosyncratic volatility computed at time $t$ to predict consumption growth at several horizons. We start with one-year-forward consumption growth from year $t$ to $t+1$. Then, we extend the forecasting horizon by looking at the annualized consumption growth from year $t$ to $t+h$, where $h=\{3,5,10\}$. Other predictors of growthlog per capita GDP and secondary school enrollment - are also measured at time $t$, while the investment share of GDP and fertility are averaged over the period concurrent with beta.

\subsection{Descriptive Statistics}

Table 1 presents descriptive statistics for all variables employed in our analysis. Means of consumption growth at different horizons are all about 2.2 percent, but measures of variability decrease as we extend the horizon. The standard deviation of consumption growth decreases by almost two-thirds from the 1-year to 10-year horizon. The mean beta equals 0.75 , and the mean idiosyncratic volatility equals 4.78 percent. The dispersion of these risk measures is large, as seen by their respective standard deviations (2.6 and 3.5 percent).

Figure 1 shows world consumption growth and world volatility. World volatility has declined since the mid-1980s, as also observed by Stock and Watson (2005). Figure 2 shows the time-series of cross-sectional medians of our risk measures. The median beta is relatively high in the early 1970s and 1980s at about 1. After 1990, beta declines sharply 
coinciding with the declining pattern observed in the correlation between national and world consumption growth. The plot of idiosyncratic volatility suggests an upward-sloping trend; however, the last panel with the number of countries in the sample clarifies the fact that the increase in volatility starting in the 1960s is most probably caused by the addition of less-developed countries to the sample. After 1970, there is no trend, or the trend is only slightly upward-sloping.

\section{Results}

\subsection{Portfolios based on Beta and Idiosyncratic Volatility}

It is standard in the finance literature to work with portfolios of stocks rather than with individual stocks (see for, example, Fama and French (1992)). This can reduce measurement error in estimated risk measures such as beta, and at the same time, it is a good way to summarize the stylized facts in the data. For convenience, we keep the term "portfolio" despite the fact that an investor cannot actually invest in the portfolios that we describe. In this section, we work with growth forecasts at 5 -year intervals.

We form beta portfolios in the following way. Every year $t=\{1960,1965, \ldots, 1995\}$ we sort countries into 5 bins according to the quintile breakpoints of the distribution of betas. This sort is repeated for every $t$, and, therefore, a country can move from one portfolio to the other over time, depending on how its beta changes. ${ }^{9}$ Then, we compute the average of future consumption growth (in the 5-year interval that follows each $t$ ), the average beta, and average idiosyncratic volatility across countries in each portfolio. The portfolio mean is the equally-weighted average of country observations assigned to that portfolio. We repeat the same procedure to obtain idiosyncratic volatility portfolios and portfolios based on different numbers of breakpoints.

The top panel of table 2 summarizes the characteristics of the 5 beta portfolios. Con-

\footnotetext{
${ }^{9}$ See the appendix for the transition matrix of beta and idiosyncratic volatility portfolios.
} 
sumption growth steadily increases from portfolio 1 (lowest betas) to portfolio 4 . There is a decline in growth when going from portfolio 4 to 5 (highest betas). However, the spread in growth between portfolios 1 and 5 is still sizeable (45 basis points).

Figure 3 plots mean consumption growth and mean beta for these 5 portfolios along with an OLS line of the corresponding relationship. This is an empirical counterpart to equation (17) in the theory section. The slope is positive indicating that there is a reward for taking risk. We also plot the line that passes through the market portfolio (which by definition has a beta of 1) and through the zero-beta portfolio growth implied by the estimated OLS line. This second line is a benchmark for the risk-growth tradeoff. ${ }^{10}$

The estimated relationship is flatter than the benchmark. According to equation (17) and assuming $\psi=0$, the slope of the benchmark line implies a premium on the world portfolio of 0.60 percent, while the OLS line implies a premium of only 0.15 percent. ${ }^{11}$ The difference in slopes can be explained by attenuation bias if betas are measured with error. It is clear that portfolios with extreme betas, which is potentially a sign of measurement error, are those that are farther away from the benchmark. Another possibility is that there are more factors that explain the cross-section of consumption growth and that blur the simple relationship implied by the theory.

A similar situation is observed in tests of the CAPM. ${ }^{12}$ The CAPM implies that high beta stocks should have higher average returns, but empirically it fails in two ways: (1) The relationship between betas and average returns is flat instead of upward sloping, and (2) Other factors can explain the spread in average returns. This second failure alone is not

\footnotetext{
${ }^{10}$ In the CAPM the line that relates average returns with betas is called the Security Market Line (SML). It is standard to contrast the SML estimated from the data with a theoretical SML that prices exactly the market (beta equal to 1) and the risk-free rate (beta equal to 0 , or the intercept of the line). In our application the intercept is the first term in equation (17), which includes the world interest rate, but also preference parameters. Since preferences are not observable, the intercept of the theoretical line cannot be determined purely from looking at the data. For this reason we take the zero-beta portfolio growth from the estimated OLS, which amounts to comparing only the slopes of the two lines.

${ }^{11}$ Both numbers are admittedly low when compared to average excess returns in international stock markets. This is just another way of stating the equity premium puzzle: when compared to consumption data, stocks seem to earn returns that are too high.

${ }^{12}$ See Cochrane (2001), ch. 20, for a survey of empirical tests and their interpretation.
} 
necessarily the tombstone of the CAPM, but it suggests the need for an augmented model in the style of Merton's ICAPM (1973). In Merton's model, other factors together with a stock's beta have power to explain average returns because they capture changes in future investment opportunities. In an analogous way, we can argue that the failure of world betas to account for all differences in average consumption growth implies that the simple model in the previous section needs to be extended to include multiple factors.

An indication of the presence of more factors is seen in the bottom panel of table 2 where we sort portfolios by idiosyncratic volatility. While there is no pattern in average betas across these portfolios, consumption growth is clearly lower in portfolios with relatively higher volatility. If volatility were just due to measurement error there should be no discernible pattern in average growth across these portfolios. Total and idiosyncratic volatility increase together, therefore table 2 corresponds also to the finding in Ramey and Ramey (1995) that volatility is bad for growth.

An important fact that emerges from table 2 is that beta and volatility are not highly correlated. The in-sample correlation between the two measures is 0.08 . The pattern relating betas and volatilities is similar to an inverted u-shape: countries with low and high betas have high volatility, and countries with medium-size betas have relatively low volatility (See figure 4). Since beta and volatility are close to being independent, we are able to test for separate effects on these two measures of risk.

In table 3 we form 9 portfolios based on three groups of beta and three groups of idiosyncratic volatility. This maintains a reasonable number of observations per portfolio (above 30). The same patterns can be observed here. Average consumption growth tends to increase with beta and decrease with idiosyncratic volatility. Idiosyncratic volatility is fairly constant across beta portfolios in the same volatility group, therefore volatility cannot explain the tendency of growth to increase with beta. Beta still varies across volatility portfolios in the same beta group. However, beta has a hard time explaining the declining pattern of growth within the medium- and high-beta groups. For instance, variation in beta goes 
in the wrong direction in the high-beta group: beta increases as we move from low to high volatility, but average growth decreases.

Given the results in tables 2 and 3 , beta and idiosyncratic volatility seem like good candidates to account for differences in average consumption growth. Figure 5 illustrates their strength as predictors by plotting the actual growth of the 9 portfolios against the predicted growth from a regression with beta and idiosyncratic volatility. ${ }^{13}$ In a perfect model, the points should align across the 45-degree line. In this case the fit is quite good, as indicated by an $R^{2}$ of 79 percent. The lower panels show the same 9 portfolios connected within beta or volatility groups. The model performs worse in the medium volatility portfolios, while the rest of the points are relatively close to the 45 degree line.

So far, we have shown differences in consumption growth for the average country in each portfolio, but differences are also observable across most of the distribution. Figure 6 shows the fitted density and cumulative distribution of growth in high- and low-beta portfolios. The distribution of growth is shifted to the left in the low-beta portfolio compared to the high-beta portfolio, which indicates that low-beta countries have lower growth more than just on average. The same can be said about volatility portfolios. High volatility countries have a higher incidence of lower growth than low volatility countries, and this difference is not only for the mean of the distribution. ${ }^{14}$

A related concern is whether the spread in growth produced by beta and volatility comes from a particular episode in recent history. Figure 7 shows the spread between high- and low-beta (volatility) portfolios at 5-year intervals. The gray areas are periods when the spread is positive (negative) in beta (volatility) portfolios. The spread, although varying in magnitude, is positive (negative), as expected, over most of our sample (1965-1990). In the early and later part of the sample we observe some small reversals. In any case, it is clear that the numbers in the tables are not driven by one particular period.

\footnotetext{
${ }^{13}$ The predicted growth comes from the OLS fitted values of the following regression at the level of portfolio averages: $\Delta c_{i}=b_{0}+b_{1} \beta_{i}+b_{2} \sigma_{i}^{\varepsilon}$, where $i=1, \ldots, 9$.

${ }^{14}$ Another way to put this is that the difference in means across portfolios is not due to skewness in the distributions.
} 
As a final example, we present in figure 8 the experience of two countries-Argentina and the U.S. This figure shows the time series of beta and growth for each country. Note that for each year $t$, beta is computed with a backward-looking window of 10 years, and average consumption growth with a forward-looking window of 5 years. For example, the beta for the year 1970 is computed with data for 1961-1970 and consumption growth corresponds to the period 1971-1975. Consumption growth is reported relative to the world's growth. If there were no measurement error, the lines for beta and relative growth should coincide according to the model. ${ }^{15}$ While the fit is not perfect, both beta and growth tend to move together. For example, the U.S. beta increases in 1980 up to almost 2, and at the same time, U.S. growth is close to 50 percent higher than the world's growth. When beta comes down in 1985 and 1990, so does growth. In the case of Argentina, beta and growth move closely together until 1980. For example, the low beta of 1980 - a product of the 1970s - correctly forecasts the low growth in the first half of the 1980s. In 1985, beta predicts more rapid growth than the actual, but in 1990 there is a perfect match between the two. Overall, this evidence suggests that risk measures and subsequent growth are more than casually connected.

\subsection{Regression Analysis}

In order to test the relationship between beta, volatility, and growth we run the following panel regression:

$$
\Delta c_{j, t+h}=b_{1} \beta_{j, t}+b_{2} \sigma_{j, t}^{\varepsilon}+\theta_{t}+\lambda_{j}+\zeta_{j, t}
$$

The dependent variable is annualized consumption growth for country $j$ between $t$ and $t+h$. We consider horizons between 1 and 10 years. The intervals for growth observations do not overlap so regressions with longer horizons have fewer observations. All regressions include time fixed effects $\left(\theta_{t}\right)$, and most regressions include country fixed effects $\left(\lambda_{j}\right)$. We

\footnotetext{
${ }^{15}$ Strictly speaking, both lines should "almost" coincide since the intercept in equation (17) is small compared to the magnitude of beta. The relative growth line should be $g_{j} / g^{*}$ where $g^{*}$ is obtained from (17) by setting $\beta=1$.
} 
allow for heterogeneity in $\zeta_{j, t}$. We also consider the case of clustering standard errors by country. This can correct, at least partially, for the serial correlation in residuals introduced by estimation error in beta and volatility. Measurement error can persist for several periods since beta and volatility are estimated with overlapping windows (except for $h=10$ ). We do not cluster by the time dimension, that is, to allow residuals in a period to be correlated across countries, because it produces biased standard errors when the number of cross-sections is small as in the case of 5- or 10-year horizons (Petersen (2006)).

Table 4 presents regressions at different horizons and with different specifications. The coefficient of beta increases up to the 5-year horizon, and then it comes down in the 10-year regression. The magnitude of these coefficients implies that a one standard deviation shock in beta increases average consumption growth by 30-40 basis points ( 5 -year horizon estimates). The coefficients on volatility are larger in absolute sense at the 3-year horizon, and then decline as the horizon is extended. The magnitude of the volatility coefficient implies that a one standard deviation shock in volatility decreases average consumption growth by 4050 basis points (5-year horizon estimates). Significance is stronger at the 5-year horizon, particularly for beta. At the 1-year horizon it is hard to find significant coefficients given the large fluctuations of consumption.

The country fixed effects do not have a big impact on the coefficients of beta and volatility. It is understandable that the fixed effects do not affect the coefficient on beta or volatility since there is substantial variation within country, as seen in the examples of Argentina and the U.S. and the portfolio transition matrices reported in the appendix. If anything, coefficients increase in magnitude after the fixed effects are included. Clustering standard errors does not make a big difference either. 


\subsection{Other Determinants of Growth}

\subsubsection{Conditional Convergence}

Regressions like (19) have a long history in the empirical growth literature that tests the predictions of the neoclassical growth model (Solow (1956)). A key variable of interest in this literature is initial income. Solow's model predicts convergence, that is, rich countries should grow at a slower pace. While this hypothesis is rejected by the data, previous papers show that there is conditional convergence (Barro (1991)). Rich countries grow at a slower pace after controlling for variables related to policy and endowments, which affect the steady state towards which the country converges.

Table 5 presents evidence of conditional convergence in our sample. The regressions without country fixed effects show a positive coefficient on initial GDP that is against absolute convergence. However, the coefficient on initial GDP becomes negative when the country fixed effects are included. The fixed effects capture the slow-moving or permanent characteristics that differentiate the steady state to which each country is converging. Beta and volatility retain their magnitude and significance at both the 5- and 10-year horizons.

\subsubsection{Fertility, Education, and Investment Share}

We can also try to measure directly the country characteristics that shift the steady state. We focus on measures of fertility, human capital (secondary school enrollment), and the investment share of GDP, which are the variables that have the most explanatory power in growth regressions (Athanasoulis and van Wincoop (2000)), Ramey and Ramey (1995)). As seen in table 6 , these variables are absorbed by the country fixed effects, given their slow-moving behavior. In other words, it is not possible to distinguish their influence from the country fixed effect that captures any unobservable slow-moving country characteristic. When the fixed effects are excluded they regain explanatory power, in particular fertility 
and the investment share. ${ }^{16}$ However, it is difficult to identify precisely the effect of each variable since they are highly correlated (Levine and Renelt (1992), Mankiw (1995)). Multicollinearity can be a more severe problem for proxies that have substantial measurement error, like our risk variables. In this sense it is perhaps not surprising that volatility is not a significant variable in the regressions without country fixed effects (last column of table 6). Beta, on the other hand, is still significant probably because its correlation with other country characteristics is much smaller (see the appendix for the correlation matrix of the country variables). Given these concerns, and for the purpose of studying the effect of risk measures on average growth, it seems better to use country fixed effects rather than direct, although still noisy, determinants of each country's steady state.

Another way to compare the explanatory power of these other variables is by predicting the consumption growth of the 9 portfolios based on beta and volatility. Figure 9.1 shows the result for each variable individually. Fertility produces the highest $R^{2}$ (49 percent) and the investment share the lowest $R^{2}$ (28 percent). When combined these variables give an $R^{2}$ of 63 percent, which is still lower than the 79 percent obtained with beta and volatility (figure 9.2). Clearly these other variables have some explanatory power, but they cannot completely substitute for the measures of risk.

\section{Risk-Taking and Country Characteristics}

\subsection{Beta, Volatility, and Development}

This section studies the correlation between our measures of risk and economic development (per capita GDP). Acemoglu and Zilibotti (1997) argue that the early stages of development are characterized by low risk-taking, because of self-insurance motives. This section shows

\footnotetext{
${ }^{16}$ The coefficient on initial GDP changes by about a factor of 4 when adding the country fixed effects to the regressions with other growth determinants and time fixed effects. This is consistent with previous papers in the empirical growth literature, in particular Caselli, Esquivel and Lefort (1996), and Islam (1995) who use panel data techniques.
} 
that beta, or international risk-taking, is not a privilege of developed countries; however rich countries have clearly lower idiosyncratic volatilities. The findings in Koren and Tenreyro (2005), although related to domestic risk-taking in the productive structure of the country, are in line with our results on volatility and development.

In figure 10, we show the distributions of betas and idiosyncratic volatilities for rich and poor countries based on their real per capita income in 1990. As can be seen in the top panel, rich countries have a slightly higher mean beta than poor countries. While betas of rich countries are more concentrated around their mean, the dispersion in betas of poor countries is much higher, spreading out farther than the distribution of rich countries in both extremes. The bottom panel confirms the fact that poor countries are characterized by higher volatility than rich countries.

In table 7 , we sort into portfolios based on the risk measures and income to illustrate these differences. Consumption growth increases with income, which confirms the failure of absolute convergence. Higher-beta countries are rewarded with higher consumption growth in the poor and rich groups; the pattern is reversed in the middle-income group. The spread in portfolio betas among rich countries equals 3.1, which is narrower than the 5.6 spread observed among poor countries. In rich countries betas are more moderated on both ends of the distribution. Rich countries have a lower frequency of low betas (37 vs. 76 observations), which explains their slightly higher average beta. The frequency of high betas is about the same in rich and poor countries.

Table 7 also shows that idiosyncratic volatility clearly decreases as countries become more developed. A majority of rich countries are in the low-volatility group, while the opposite is true for poor countries. This implies that it may be hard to disentangle the effects of volatility and income, or other variables highly correlated with income such as fertility or education levels, as seen in the regressions in table 6. This concern does not apply to beta, since beta and income are not highly correlated. 


\subsection{Beta, Volatility, and Financial Integration}

As we establish in the model, countries that invest more in foreign risky technologies enjoy higher expected consumption growth. Throughout the paper, we use beta as a measure of this risk-taking position, since in the model beta corresponds to the fraction of wealth allocated to the world mutual fund. However, the question remains whether beta and direct measures of portfolio allocations are in fact such good correlates. To explore the relationship between these two, we use estimates of stocks of foreign assets and liabilities at the country level compiled by Lane and Milesi-Ferretti (2001). Despite the careful and detailed data construction they perform, we need to recognize that their measures represent only proxies for variables in the model. Nevertheless, if our measures of risk have an effect on consumption growth through the channel of financial integration, we at least expect to find a positive correlation between risk-taking and foreign asset positions. ${ }^{17}$

First, we examine the basic patterns of financial integration for the 9 portfolios sorted by beta and idiosyncratic volatility. The top panel of Table 8 shows that countries with high betas hold larger stocks of foreign assets over GDP. Conversely, countries with high idiosyncratic volatility tend to hold smaller stocks of foreign assets. Patterns of foreign liabilities across portfolios are not as strong. Differences are again observable for the net external position (with the reversed sign), with the exception of the high-beta-high-volatility portfolio that has an unusually high level of debt.

An important difference between assets and liabilities is that liabilities include a disproportionate fraction of government debt owned by foreigners, while assets are closer to private decisions. ${ }^{18}$ The measure of assets seems cleaner for the study of private - as op-

\footnotetext{
${ }^{17}$ For example, $\beta=0.75$ taken literally implies that $75 \%$ of a country's wealth is invested in the world mutual fund of risky assets. A first obstacle in contrasting betas with Lane and Milesi-Ferretti's measures is that these are reported as fractions of GDP and not of total wealth of the country. Also, the distinction between risky and risk-free investments that is made in the model is not straightforward to apply to the data. A final minor point, except perhaps for the U.S., is that these measures consider only foreign investments, but are not corrected for the country's own position in the world mutual fund. If a country is big, this adjustment can be considerable.

${ }^{18}$ See the appendix for more evidence on the importance of government debt as a fraction of total external debt.
} 
posed to public - consumption growth.

We also report the results from regressions where the measures of financial integration are the dependent variables. These regressions represent an organized way of reporting correlations, but they do not have the forecasting intention of the regressions with consumption growth and do not imply causality. Assets and liabilities are taken at 5- or 10-year intervals and are measured in the last year of the estimation window used for beta and volatility. We add time fixed effects to the regressions because of the upward trend in integration throughout the sample period (see figure 11). We do not include country fixed effects because of the slow-moving feature of these stock measures.

Table 9 confirms that beta and the stock of foreign assets are positively related, while volatility and assets are negatively related. Coefficient estimates using 5-year intervals imply that a one-standard-deviation increase in beta is associated with a 3.3 percentage-point increase in the ratio of foreign assets to GDP. A one-standard-deviation increase in idiosyncratic volatility is associated with an 8.7 percentage-point decrease in the same ratio. Figure 11 shows that the spread in foreign asset holdings is present across most time periods between high- and low-beta countries, and also between high- and low-volatility countries.

The results with foreign liabilities and the net external position are weaker. There is a positive but insignificant correlation between beta and foreign liabilities, which may explain why the regression with the next external position also shows an insignificant coefficient for beta. The effect of volatility on the next external position comes mostly from decreasing assets rather than from increasing liabilities.

Given that highly volatile countries have worse net external positions, we speculate that a model where risk-sharing is limited by solvency constraints, perhaps in the style of Alvarez and Jermann (2000), can account for the negative effect of volatility on future consumption growth. The basic idea would be the following. A country hit by an idiosyncratic shock borrows to smooth the shock. However, its borrowing is limited to keep the country's position solvent or sustainable if the country wants to remain financially integrated with the rest of 
the world. The solvency constraints limit present risk-sharing and consumption deviates from world consumption. At the same time, these constraints can limit future growth if they also apply to borrowing destined for productive investments. Therefore, a country may face a tradeoff between smoothing the current shock more fully and saving borrowing capacity for future growth.

As a last step, we look at the relationship between foreign assets and expected consumption growth in table 10. The regressions are analogous to those in table 4, although they do not include country fixed effects. In the regression with a 5-year horizon, a onestandard-deviation increase in foreign assets predicts an increase of 28 basis points in average consumption growth. This coefficient is significant at the 5 percent level. The coefficient at 10-year horizon is smaller, but still significant at the 10 percent level. This analysis confirms that financial integration is correlated with higher expected consumption growth, in particular through the risk-shifting opportunities that it provides.

\section{Conclusions}

This paper shows that there are risk-growth tradeoffs in cross-country consumption data. Countries that have higher betas with world consumption are rewarded with higher expected consumption growth. However, countries with high idiosyncratic consumption volatility see their future consumption growth reduced on average.

The first tradeoff that we identify is consistent with models of international financial integration. It highlights the benefits of financial integration as suggested by previous estimates. Our results are also important given the significance of the world portfolio emphasized by Athanasoulis and Shiller (2000).

The lack of a tradeoff between idiosyncratic volatility and expected consumption growth is more challenging theoretically. If markets are complete, idiosyncratic shocks should affect neither present nor future consumption opportunities. However, our results indicate that 
imperfect risk-sharing has persistent negative effects. 


\section{Appendix}

This appendix presents several robustness checks and supplementary data.

- Regions

We test the relationship between beta, idiosyncratic volatility and expected consumption growth at the level of regions motivated by papers that use geographically-defined groups to examine risk-sharing (e.g. Obstfeld (1994b)). We assign countries to 5 regions - Africa, Asia, Latin America, Middle East, or OECD (except Asian countries) - and run the regression of regional average 5-year future consumption growth on regional average beta and idiosyncratic volatility. Figure A1 plots the actual consumption growth by region versus the predicted. The $R^{2}$ of 67 percent suggests that the fit of the model is quite strong. Asian and OECD countries lie very close to the 45 degree line; only African countries are further away from it.

\section{- Consumption Data without PPP Adjustment}

We use country-level and world consumption growth from WDI to show that our results survive even after stripping off the effect of prices. Table A1 reports the results of countryand time-fixed effects regressions with 5- and 10-year forecasting horizons. The coefficient on beta doubles compared to the PWT dataset and it is significant at the 1 percent level. Idiosyncratic volatility, however, loses its significance. Figure A2 confirms that the spread in consumption growth between high and low beta countries is always positive while the spread between high and low idiosyncratic volatility countries is negative in all but one period.

\section{- Beta and Volatility Measurement}

This section summarizes alternative measures of beta and volatilities and their power to predict consumption growth (Table A2). The main issue when estimating beta is to define the estimation window. In the main text we use a 10-year window; here we show results with 5- and 15-year windows. The mean beta obtained using the three different windows is 
very similar, ranging between 0.72 and 0.86 . However, the standard deviation drops from 4.6 for the 5 -year window to 1.9 for the 15 -year window beta. The coefficient on beta in our basic regression is between 2-5 basis points for the 5 -year beta and 20-28 basis points for the 15-year beta.

Risk-sharing papers sometimes test the response of domestic consumption growth to world GDP growth rather than to world consumption growth (e.g., Obstfeld (1994a)). Here we present results with betas on world GDP growth. The effect of world GDP beta on consumption is slightly higher as it ranges from 16 to 21 basis points. At both horizons, it is significant at the 5 percent level.

Motivated by the finance literature (e.g., Fama and French (1992)) we also run regressions where instead of the country beta we use the average beta of the portfolio to which the country belongs in year $t$. We use average betas and idiosyncratic volatilities from 9 portfolios (3x3 sort) and 25 portfolios (5x5 sort) based on these two variables. The average betas and volatilities for 9 portfolios are those reported in table 3 . In the regression with the 5 -year horizon, coefficients on both beta and idiosyncratic volatility are preserved (although the statistical significance is reduced with this procedure). This leads us to believe that the main estimates in the paper are not driven by outliers.

\section{- Additional Growth Determinants}

In this section we test the robustness of our risk measures against a set of additional growth determinants. To the independent variables in our panel regression, we add 10year averages (concurrent with beta) of government expenditure as a share of GDP (PWT mnemonic kg), openness to trade (PWT mnemonic openk), inflation measured as the change in GDP deflator (WDI), private credit over GDP (Beck, Demirgüç-Kunt and Levine (2000)) and a democracy indicator (Jaggers and Marshall (2003)). We report results for 5-year forecasting horizon (Table A3). Beta preserves its significance in all but one of the regressions and also its coefficient remains at a level similar to the previous analysis. While idiosyncratic volatility enters with a similar coefficient and mostly significantly in the country- and time- 
fixed effects regressions, its power diminishes in the regressions without country-fixed effects. Of the additional growth determinants, only government expenditure as a share of GDP and inflation are significant in the time- and country-fixed effects regressions. Openness to trade and private credit show higher predictive power in the regressions without country-fixed effects.

- Public Versus Private External Debt

Table A4 makes the distinction between private and public external debt of countries. Whereas private debt averages at only about 3-4 percent of GDP, public debt ranges between 20 to 70 percent of GDP. The fact that private debt forms only a tiny proportion of the total may explain why our regressions with foreign liabilities do not work as well as those with foreign assets. These data are taken from the WDI. The sample covers 47 countries in 1970-2000, although the time series is shorter for some countries. 


\section{References}

[1] Acemoglu, D., and F. Zilibotti (1997), Was Prometheus Unbound by Chance? Risk, Diversification, and Growth, Journal of Political Economy 105, 709-751.

[2] Alvarez, F. and U. Jermann (2000), Efficiency, Equilibrium, and Asset Pricing with Risk of Default, Econometrica 68, 775-797.

[3] Athanasoulis, S. and R. Shiller (2000), The Significance of the Market Portfolio, Review of Financial Studies 13, 301-329.

[4] Athanasoulis, S. and R. Shiller (2001), World Income Components: Measuring and Exploiting Risk-Sharing Opportunities, American Economic Review 91, 1031-1054.

[5] Athanasoulis, S. and E. van Wincoop (2000), Growth Uncertainty and risk-sharing, Journal of Monetary Economics 45, 477-505.

[6] Barro, R. (1991), Economic Growth in a Cross-Section of Countries, Quarterly Journal of Economics 106, 407-443.

[7] Barro, R., and J.W. Lee (2001), International Data on Educational Attainment: Updates and Implications, Oxford Economic Papers 53, 541-563

[8] Beck, T., A. Demirgüç-Kunt, and R. Levine (2001), The Financial Structure Database, in Financial Structure and Economic Growth: A Cross-Country Comparison of Banks, Markets, and Development, edited by A. Demirgüç-Kunt and R. Levine. Cambridge, MA: MIT Press.

[9] Caselli, F., G. Esquivel, and F. Lefort (1996), Reopening the Convergence Debate: A New Look at Cross-Country Growth Empirics, Journal of Economic Growth 1, 363-389.

[10] Cochrane, J. (1991), A Simple Test of Consumption Insurance, Journal of Political Economy 99, 957-976. 
[11] Cochrane, J. (2001), Asset Pricing, Princeton: Princeton University Press.

[12] Cox, J.C., J.E. Ingersoll and S. Ross (1985), An Intertemporal General Equilibrium Model of Asset Prices, Econometrica 53, 363-384.

[13] Duffie, D. and L. Epstein (1992a), Stochastic Differential Utility, Econometrica 60, 353394.

[14] Duffie, D. and L. Epstein (1992b), Asset Pricing with Stochastic Differential Utility, Review of Financial Studies 5, 411-436.

[15] Fama, E. and K. French (1992), The Cross-Section of Expected Stock Returns, Journal of Finance 47, 427-465.

[16] Fama, E. and J. MacBeth (1973), Risk, Return and Equilibrium: Empirical Tests, Journal of Political Economy 81, 607-636.

[17] Fuhrer, J. and M. Klein (1998), Risky Habits: On Risk Sharing, Habit Formation, and the Interpretation of International Consumption Correlations, NBER Working Paper No. 6735. Forthcoming (2006) in the Review of International Economics.

[18] Islam, N. (1995), Growth Empirics: A Panel Data Approach, Quarterly Journal of Economics 110, 1128-1170.

[19] Jaggers, K., and M. Marshall (2003), Polity 4 Project, Center for International Development and Conflict Management, University of Maryland.

[20] Koren, M. and S. Tenreyro (2005), Volatility and Development, CEPR Discussion paper No. 5307. Forthcoming in the Quarterly Journal of Economics.

[21] Lane, P. and G. Milesi-Ferretti (2001), The External Wealth of Nations: Measures of Foreign Assets and Liabilities for Industrial and Developing Countries, Journal of International Economics 55, 263-294. 
[22] Levine, R. and D. Renelt (1992), A Sensitivity Analysis of Cross-Country Growth Regressions, American Economic Review 82, 942-963.

[23] Lewis, K. (1996), What Can Explain the Apparent Lack of International Consumption Risk Sharing? Journal of Political Economy 104, 267-297.

[24] Lewis, K. (1999), Trying to Explain Home Bias in Equities and Consumption, Journal of Economic Literature 37, 571-608.

[25] Mace, B. (1991), Full Insurance in the Presence of Aggregate Uncertainty, Journal of Political Economy 99, 928-956.

[26] Mankiw, G. (1995), The Growth of Nations, Brookings Papers on Economic Activity 1, 275-326.

[27] Merton, R.C. (1971), Optimum Consumption and Portfolio Rules in a Continuous Time Model, Journal of Economic Theory 3, 373-413.

[28] Merton, R.C. (1973), An Intertemporal Capital Asset Pricing Model, Econometrica 41, 867-887.

[29] Obstfeld, M. (1994a), Are Industrial Country Consumption Risks Globally Diversified? in Leonardo Leiderman and Assaf Razin, eds., Capital Mobility: The Impact on Consumption, Investment and Growth. Cambridge: Cambridge University Press, 13-44.

[30] Obstfeld, M. (1994b), Risk-Taking, Global Diversification, and Growth, American Economic Review 84, 1310-1329.

[31] Petersen, M. (2006), Estimating Standard Errors in Finance Panel Data Sets: Comparing Approaches, Working Paper Northwestern University.

[32] Ramey, G. and V. Ramey (1995), Cross-Country Evidence on the Link Between Volatility and Growth, American Economic Review 85, 1138-1151. 
[33] Solow, R. (1956), A Contribution to the Theory of Economic Growth, Quarterly Journal of Economics 70, 65-94.

[34] Stock, J. and M. Watson (2005), Understanding Changes in International Business Cycle Dynamics, Journal of the European Economic Association 3, 968-1006.

[35] Tobin, J. (1958), Liquidity Preference as Behavior towards Risk, Review of Economic Studies 25, 68-95.

[36] Yogo, M. (2004), Estimating the Elasticity of Intertemporal Substitution when Instruments are Weak, Review of Economics and Statistics 86, 797-810. 


\section{Table 1}

\section{Descriptive Statistics for Consumption Growth, Measures of Risk, Common Predictors of Consumption Growth and Measures of Financial Integration}

The sample covers 74 countries from 1960 to 2000 (the years 1950-1959 are used only for the estimation of risk measures). Consumption is computed as a product of real per capita GDP in constant laspeyres prices (PWT mnemonic: rgdpl) and consumption share of rgdpl (PWT mnemonic: $k c$ ). Consumption growth is computed as a simple growth rate. Annualized consumption growth over non-overlapping 3-, 5-, and 10year intervals are also reported. The rest of the variables are summarized in reference to the sample with 5year intervals of consumption growth. World consumption growth is calculated as a total-consumptionweighted average of national per capita consumption growth rates. Beta is the regression coefficient of a country's consumption growth on world consumption growth using a backwards 10-year moving window (years t-9 to t). Idiosyncratic volatility is defined as the standard deviation of residuals from that regression. World consumption growth volatility is the standard deviation of world consumption growth using a backwards 10-year moving window. The correlation reported is between a country's consumption growth and world consumption growth, measured concurrently with beta. Log GDP is the log of rgdpl taken at time t. Investment/GDP is the investment share of rgdpl (PWT mnemonic: ki). Fertility is taken from World Development Indicators. Investment/GDP and log of fertility are averaged over the period t-9 to t. Secondary school enrollment, from Barro and Lee (2001), is measured in year t. Measures of the net external position and the stocks of foreign assets and liabilities relative to GDP are taken from Lane and Milesi-Ferretti (2001) at time t.

\begin{tabular}{rccccc}
\hline Variable & Obs & Mean & Std. Dev. & Min & Max \\
\hline Annual Consumption Growth (\%) & 2721 & 2.22 & 6.35 & -35.19 & 41.92 \\
3-year Average Consumption Growth (\%) & 869 & 2.23 & 3.80 & -13.78 & 19.22 \\
5-year Average Consumption Growth (\%) & 535 & 2.20 & 2.98 & -11.88 & 12.49 \\
10-year Average Consumption Growth (\%) & 258 & 2.19 & 2.20 & -6.80 & 8.68 \\
World Consumption Growth (\%) & 535 & 2.45 & 0.72 & 0.98 & 3.18 \\
Beta & 535 & 0.75 & 2.55 & -8.96 & 17.89 \\
Idiosyncratic Volatility (\%) & 535 & 4.78 & 3.46 & 0.55 & 20.16 \\
Correlation & 535 & 0.18 & 0.36 & -0.75 & 0.93 \\
Log GDP & 535 & 8.56 & 0.93 & 6.46 & 10.45 \\
World Consumption Growth Volatility (\%) & 535 & 0.97 & 0.13 & 0.73 & 1.15 \\
10-yr Average Investment/GDP (\%) & 535 & 18.28 & 8.40 & 1.93 & 56.29 \\
10-yr Average Log Fertility & 535 & 1.32 & 0.52 & 0.24 & 2.09 \\
Secondary School Enrollment & 494 & 22.23 & 15.36 & 0.80 & 69.60 \\
Net External Position (\% GDP) & 408 & -32.28 & 53.64 & -654.60 & 204.09 \\
Foreign Assets (\%GDP) & 408 & 36.79 & 68.35 & 1.56 & 833.51 \\
Foreign Liabilities (\%GDP) & 408 & 69.07 & 69.06 & 0.55 & 694.07 \\
\hline
\end{tabular}




\section{Table 2}

Means of Consumption Growth, Beta and Idiosyncratic Volatility across Portfolios Sorted by Beta (Top Panel) and Idiosyncratic Volatility (Bottom Panel)

Each year $t=\{1960,1965,1970, \ldots, 1995\}$, countries are assigned to one of five portfolios based on quintile breakpoints for the distribution of betas (idiosyncratic volatilities). Breakpoints are computed every year t from the cross-section of betas (idiosyncratic volatilities). For each portfolio, we compute the mean of consumption growth over 5-year non-overlapping intervals t+1 to t+5 (specifically, 1961-1965, 1966$1970, \ldots, 1996-2000)$; and means of beta, idiosyncratic volatility, and total volatility all measured from year t-9 to t.

\begin{tabular}{rcccc}
\hline & $\begin{array}{c}\text { Consumption } \\
\text { Growth (\%) }\end{array}$ & Beta & $\begin{array}{c}\text { Idiosyncratic } \\
\text { Volatility (\%) }\end{array}$ & $\begin{array}{c}\text { Total } \\
\text { Volatility (\%) }\end{array}$ \\
\cline { 2 - 5 } Low & \multicolumn{5}{c}{ Beta Portfolios } \\
2 & 2.70 & -2.38 & 6.28 & 6.80 \\
3 & 2.22 & -0.04 & 3.45 & 3.49 \\
4 & 2.45 & 0.72 & 3.62 & 3.73 \\
High & 2.15 & 1.53 & 3.90 & 4.26 \\
Low & 2.37 & 3.92 & 6.65 & 7.81 \\
2 & 2.69 & 0.68 & 1.38 & 1.68 \\
3 & 2.58 & 0.68 & 2.47 & 2.79 \\
4 & 1.88 & 0.64 & 3.94 & 4.34 \\
High & 1.47 & 1.08 & 5.88 & 6.42 \\
& & 0.67 & 10.30 & 10.94 \\
\hline
\end{tabular}




\section{Table 3}

Means of Consumption Growth, Beta and Idiosyncratic Volatility across Portfolios Sorted by Beta and Idiosyncratic Volatility

Each year $t=\{1960,1965,1970, \ldots, 1995\}$, countries are assigned to one of three portfolios based on tercile breakpoints of the distribution of betas (idiosyncratic volatilities). Tercile breakpoints are obtained separately (i.e. not one within the other) from the cross-section of betas and idiosyncratic volatilities every year t. For each portfolio, we compute the mean of consumption growth over 5-year non-overlapping intervals $\mathrm{t}+1$ to $\mathrm{t}+5$ (specifically, 1961-1965, 1966-1970,..., 1996-2000); and means of beta and idiosyncratic volatility, both measured from year t-9 to t. The number of observations in each portfolio is also reported.

\begin{tabular}{|c|c|c|c|}
\hline \multirow[b]{3}{*}{ Beta Portfolios } & \multicolumn{3}{|c|}{ Idiosyncratic Volatility Portfolios } \\
\hline & Low & Medium & High \\
\hline & \multicolumn{3}{|c|}{ Consumption Growth (\%) } \\
\hline$\overline{\text { Low }}$ & 2.15 & 2.44 & 1.24 \\
\hline Medium & 2.63 & 2.56 & 1.70 \\
\hline \multirow[t]{2}{*}{ High } & 2.66 & 2.22 & 2.12 \\
\hline & \multicolumn{3}{|c|}{ Beta } \\
\hline Low & -0.44 & -1.18 & -2.64 \\
\hline Medium & 0.68 & 0.76 & 0.73 \\
\hline \multirow[t]{2}{*}{ High } & 1.87 & 2.68 & 3.89 \\
\hline & \multicolumn{3}{|c|}{ Idiosyncratic Volatility (\%) } \\
\hline Low & 1.81 & 3.83 & 8.68 \\
\hline Medium & 1.65 & 3.91 & 8.09 \\
\hline \multirow[t]{2}{*}{ High } & 1.83 & 4.05 & 8.73 \\
\hline & \multicolumn{3}{|c|}{ \# Observations } \\
\hline Low & 49 & 59 & 68 \\
\hline Medium & 84 & 57 & 36 \\
\hline High & 45 & 59 & 78 \\
\hline
\end{tabular}




\section{Table 4}

The Effect of Beta and Idiosyncratic Volatility on Consumption Growth: Basic Regression

This table shows results for the panel regression in equation (19) in the text. The dependent variable is consumption growth over forward 1-, 3-, 5- or 10-year non-overlapping intervals. The independent variables are beta and idiosyncratic volatility, both measured from year t-9 to t. The sample period is $1961-2000$ and it covers 74 countries. Time fixed effects (FE) are included in all regressions. Standard errors are reported in parentheses. Significance: * $10 \%$, ** $5 \%$. *** $1 \%$.

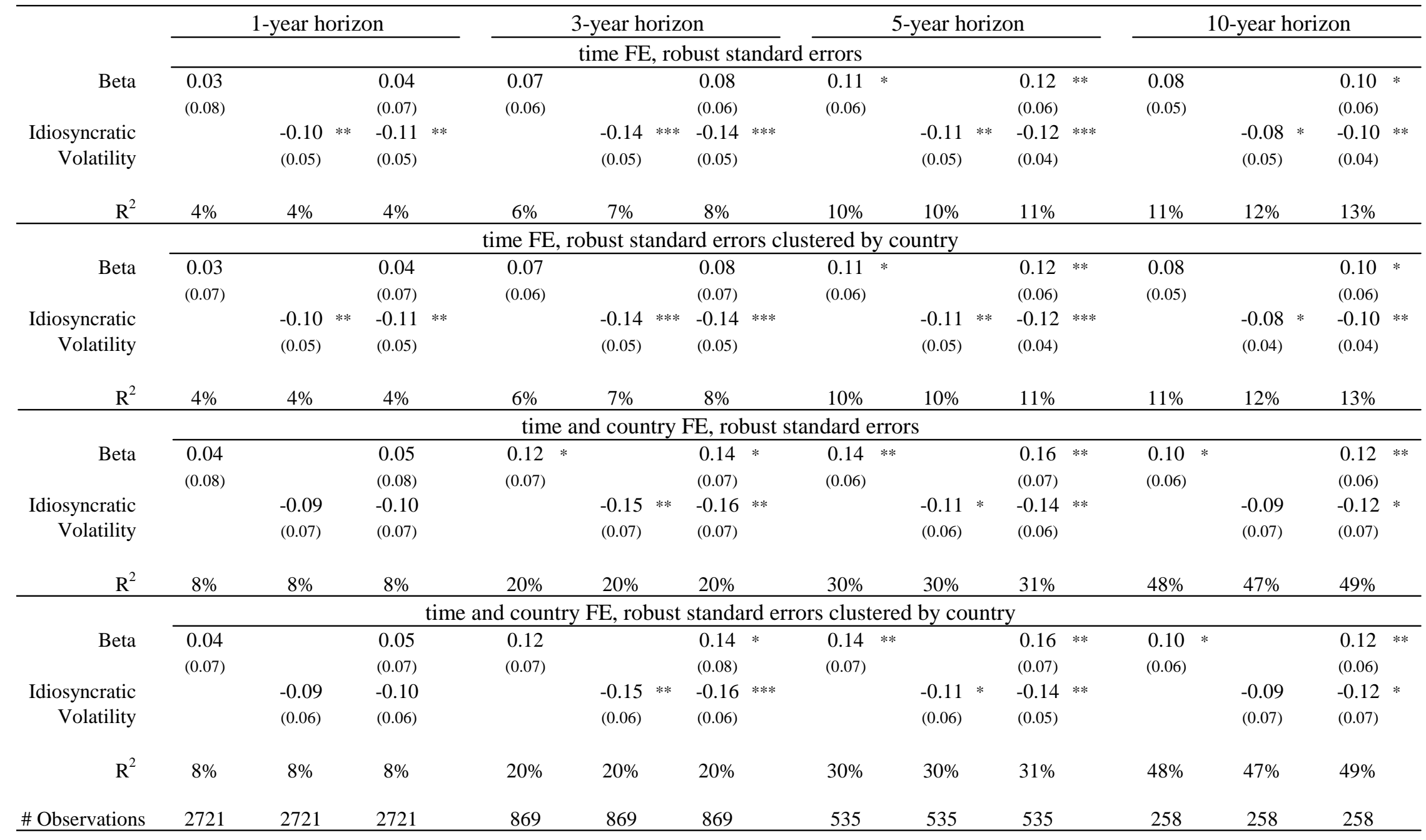




\section{Table 5}

\section{The Effect of Beta and Idiosyncratic Volatility on Consumption Growth: Accounting for Conditional Convergence}

This table shows results for the panel regression in equation (19) in the text. The dependent variable is consumption growth over forward 5- or 10-year non-overlapping intervals. The independent variables are beta and idiosyncratic volatility, both measured from year t-9 to $t$, and the log of GDP measured in year t. The sample period is 1961-2000 and it covers 74 countries. Time fixed effects (FE) are included in all regressions. Standard errors are reported in parentheses. Significance: * 10\%, ${ }^{* *} 5 \%$. ${ }^{* * *} 1 \%$.

\begin{tabular}{|c|c|c|c|c|}
\hline \multirow[b]{3}{*}{ Beta } & \multicolumn{2}{|c|}{ 5-year horizon } & \multicolumn{2}{|c|}{ 10-year horizon } \\
\hline & \multicolumn{4}{|c|}{ time FE, robust standard errors } \\
\hline & 0.11 & * & 0.08 & \\
\hline & $(0.06)$ & & $(0.06)$ & \\
\hline \multirow[t]{2}{*}{ Idiosyncratic Volatility } & -0.08 & * & -0.06 & \\
\hline & $(0.05)$ & & $(0.04)$ & \\
\hline \multirow[t]{2}{*}{ Log GDP } & 0.33 & ** & 0.29 & * \\
\hline & $(0.14)$ & & $(0.15)$ & \\
\hline \multirow[t]{2}{*}{$\mathrm{R}^{2}$} & $12 \%$ & & $14 \%$ & \\
\hline & \multicolumn{4}{|c|}{ time FE, robust standard errors clustered by country } \\
\hline \multirow{4}{*}{ Idiosyncratic Volatility } & 0.11 & * & 0.08 & \\
\hline & $(0.06)$ & & $(0.06)$ & \\
\hline & -0.08 & * & -0.06 & \\
\hline & $(0.05)$ & & $(0.04)$ & \\
\hline \multirow[t]{2}{*}{ Log GDP } & 0.33 & * & 0.29 & * \\
\hline & $(0.17)$ & & $(0.17)$ & \\
\hline \multirow[t]{2}{*}{$\mathrm{R}^{2}$} & $12 \%$ & & $14 \%$ & \\
\hline & \multicolumn{4}{|c|}{ time and country FE, robust standard errors } \\
\hline \multirow{4}{*}{ Idiosyncratic Volatility } & 0.14 & ** & 0.11 & * \\
\hline & $(0.07)$ & & $(0.06)$ & \\
\hline & -0.16 & $* * *$ & -0.14 & $* *$ \\
\hline & $(0.06)$ & & $(0.07)$ & \\
\hline \multirow[t]{2}{*}{ Log GDP } & -2.81 & $* * *$ & -2.98 & $* * *$ \\
\hline & (0.73) & & $(0.84)$ & \\
\hline \multirow[t]{3}{*}{$\mathrm{R}^{2}$} & $34 \%$ & & $54 \%$ & \\
\hline & \multicolumn{4}{|c|}{ time and country FE } \\
\hline & robust & d err & red by co & \\
\hline \multirow{4}{*}{ Idiosyncratic Volatility } & 0.14 & $* *$ & 0.11 & * \\
\hline & $(0.06)$ & & $(0.06)$ & \\
\hline & -0.16 & $* * *$ & -0.14 & $* *$ \\
\hline & $(0.05)$ & & $(0.06)$ & \\
\hline \multirow[t]{2}{*}{ Log GDP } & -2.81 & $* * *$ & -2.98 & $* * *$ \\
\hline & $(0.77)$ & & $(0.84)$ & \\
\hline $\mathrm{R}^{2}$ & $34 \%$ & & $54 \%$ & \\
\hline \# Observations & 535 & & 258 & \\
\hline
\end{tabular}




\section{Table 6}

\section{The Effect of Beta and Idiosyncratic Volatility on Consumption Growth: Other Determinants of Growth}

This table shows results for the panel regression in equation (19) in the text. The dependent variable is consumption growth over forward 5- or 10-year non-overlapping intervals. The independent variables are beta and idiosyncratic volatility, both measured from year t-9 to t; the log of GDP measured in year t; investment as a share of GDP and the log of fertility rates averaged over the period t-9 to t; and secondary school enrollment measured at t. The sample period is 1961-2000 and it covers 74 countries, except for the regressions with secondary school enrollment. Time fixed effects (FE) are included in all regressions. Robust standard errors clustered by country are reported in parentheses. Significance: * 10\%, ** 5\%. *** $1 \%$.

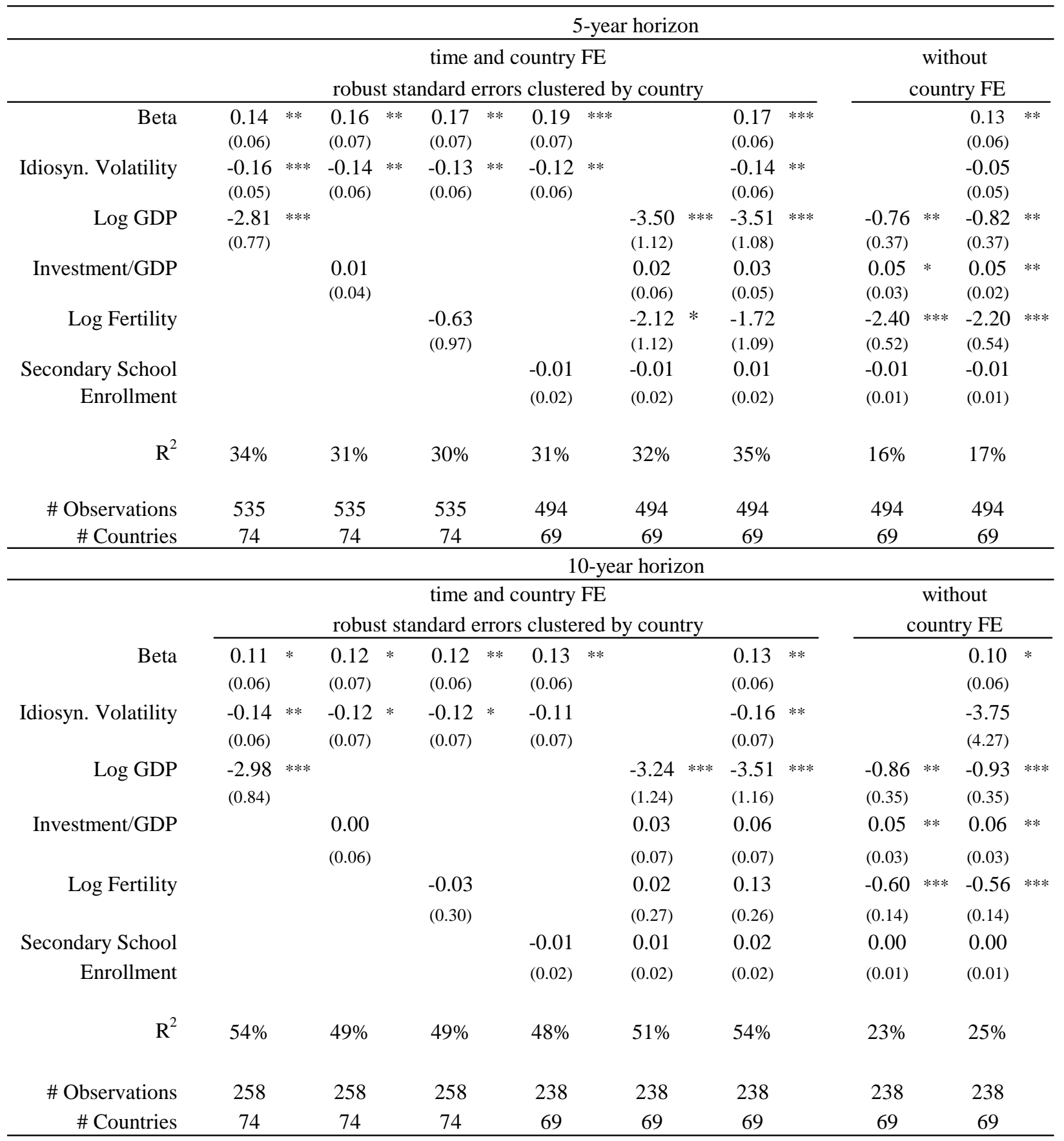


Table 7

Means of Consumption Growth, Beta and Idiosyncratic Volatility across Portfolios Sorted by Initial GDP and Beta (Left Panel) and Initial GDP and Idiosyncratic Volatility (Right Panel)

Each year $t=\{1960,1965,1970, \ldots, 1995\}$, countries are assigned to one of three portfolios based on tercile breakpoints of the distribution of real per capita GDP (betas, idiosyncratic volatilities). Tercile breakpoints are obtained separately (i.e. not one within the other) from the cross-section of these measures every year t. For each portfolio, we compute the mean of consumption growth over 5-year non-overlapping intervals $t+1$ to $t+5$ (specifically, 1961-1965, 1966-1970,.., 1996-2000); and means of beta or idiosyncratic volatility, both measured from year t-9 to t. The number of observations in each portfolio is also reported.

\begin{tabular}{|c|c|c|c|c|c|c|}
\hline \multirow[b]{3}{*}{ GDP Portfolios } & \multicolumn{3}{|c|}{ Beta Portfolios } & \multicolumn{3}{|c|}{ Idiosyncratic Volatility Portfolios } \\
\hline & Low & Medium & High & Low & Medium & High \\
\hline & \multicolumn{3}{|c|}{ Consumption Growth (\%) } & \multicolumn{3}{|c|}{ Consumption Growth (\%) } \\
\hline Poor & 1.35 & 2.32 & 1.95 & 1.85 & 2.21 & 1.43 \\
\hline Middle-Income & 2.11 & 2.02 & 1.89 & 1.87 & 2.30 & 1.76 \\
\hline \multirow[t]{2}{*}{ Rich } & 2.65 & 2.75 & 2.97 & 2.85 & 3.05 & 2.41 \\
\hline & & Beta & & \multicolumn{3}{|c|}{ Idiosyncratic Volatility (\%) } \\
\hline Poor & -2.16 & 0.69 & 3.50 & 2.06 & 3.99 & 9.15 \\
\hline Middle-Income & -1.34 & 0.70 & 3.01 & 1.83 & 3.96 & 8.37 \\
\hline \multirow[t]{2}{*}{ Rich } & -0.60 & 0.73 & 2.51 & 1.65 & 3.75 & 7.39 \\
\hline & \multicolumn{3}{|c|}{ \# Observations } & \multicolumn{3}{|c|}{ \# Observations } \\
\hline Poor & 76 & 41 & 59 & 21 & 67 & 88 \\
\hline Middle-Income & 63 & 56 & 60 & 41 & 75 & 63 \\
\hline Rich & 37 & 80 & 63 & 116 & 33 & 31 \\
\hline
\end{tabular}




\section{Table 8}

\section{Averages of Financial Integration Measures Across Portfolios Sorted by Beta and Idiosyncratic Volatility}

Each year $t=\{1970,1975, \ldots, 1995\}$, countries are assigned to one of three portfolios based on tercile breakpoints of the distribution of betas (idiosyncratic volatilities). Tercile breakpoints are obtained separately (i.e. not one within the other) from the cross-section of betas and idiosyncratic volatilities every year t. For each portfolio, we compute the mean of foreign assets/GDP, foreign liabilities/GDP, and net external position (assets-liabilities) measured in year t.

\begin{tabular}{|c|c|c|c|}
\hline \multirow[b]{3}{*}{ Beta Portfolios } & \multicolumn{3}{|c|}{ Idiosyncratic Volatility Portfolios } \\
\hline & Low & Medium & High \\
\hline & \multicolumn{3}{|c|}{ Foreign Assets (\% GDP) } \\
\hline Low & 40 & 16 & 24 \\
\hline Medium & 62 & 40 & 22 \\
\hline \multirow[t]{2}{*}{ High } & 52 & 35 & 29 \\
\hline & \multicolumn{3}{|c|}{ Foreign Liabilities (\% GDP) } \\
\hline Low & 68 & 62 & 63 \\
\hline Medium & 69 & 69 & 58 \\
\hline \multirow[t]{2}{*}{ High } & 63 & 64 & 93 \\
\hline & \multicolumn{3}{|c|}{ Net External Position (\% GDP) } \\
\hline Low & -28 & -45 & -38 \\
\hline Medium & -7 & -29 & -36 \\
\hline High & -11 & -30 & -64 \\
\hline
\end{tabular}




\section{Table 9}

\section{Relationship between Beta, Idiosyncratic Volatility and Financial Integration}

The dependent variable is one of three measures from Lane and Milesi-Ferretti (2001): (1) foreign assets/GDP, or (2) foreign liabilities/GDP, (3) net external position (assets-liabilities). These are measured in year $\mathrm{t}=\{1970,1975, \ldots, 1995)$ in the regression at 5-year intervals. Beta and idiosyncratic volatility, measured from t-9 to t, are the independent variables. The sample period is 1970-1995 and it covers data for 72 countries. All regressions include time fixed effects. Robust standard errors clustered by country are reported in parentheses. Significance: * $10 \%,{ }^{* *} 5 \%$. ${ }^{* * *} 1 \%$.

\begin{tabular}{|c|c|c|c|c|}
\hline \multirow[b]{3}{*}{ Beta } & \multicolumn{2}{|c|}{ 5-year intervals } & \multicolumn{2}{|c|}{ 10-year intervals } \\
\hline & \multicolumn{4}{|c|}{ Foreign Assets (\% GDP) } \\
\hline & 1.29 & * & 1.79 & $* *$ \\
\hline \multirow{2}{*}{ Idiosyncratic Volatility } & -2.54 & $* *$ & -2.23 & \\
\hline & $(1.25)$ & & $(1.41)$ & \\
\hline \multirow[t]{2}{*}{$\mathrm{R}^{2}$} & $6 \%$ & & $6 \%$ & \\
\hline & \multicolumn{4}{|c|}{ Foreign Liabilities (\% GDP) } \\
\hline \multirow{4}{*}{ Idiosyncratic Volatility } & 4.05 & & 3.84 & \\
\hline & $(2.65)$ & & (3.15) & \\
\hline & 1.93 & & 1.54 & \\
\hline & (1.64) & & $(1.70)$ & \\
\hline \multirow[t]{2}{*}{$\mathrm{R}^{2}$} & $18 \%$ & & $16 \%$ & \\
\hline & \multicolumn{4}{|c|}{ Net External Position (\% GDP) } \\
\hline \multirow{4}{*}{ Idiosyncratic Volatility } & -2.77 & & -2.05 & \\
\hline & $(2.79)$ & & (3.28) & \\
\hline & -4.47 & $* * *$ & -3.77 & $* *$ \\
\hline & $(1.52)$ & & $(1.60)$ & \\
\hline $\mathrm{R}^{2}$ & $17 \%$ & & $12 \%$ & \\
\hline \# Observations & 408 & & 201 & \\
\hline
\end{tabular}


Table 10

\section{The Effect of Foreign Assets on Consumption Growth}

The dependent variable is forward consumption growth at 5- or 10-year non-overlapping intervals. For the 5 -year horizon, consumption growth is measured from $t+1$ to $t+5$, where $t=\{1970,1975, \ldots, 1995\}$. The independent variable is the stock of foreign assets over GDP from Lane and Milesi-Ferretti (2001), measured at time t. The coefficient on assets is multiplied by $10^{4}$. The sample period is $1970-2000$ and it covers data for 72 countries. All regressions include time fixed effects. Robust standard errors clustered by country are reported in parentheses. Significance: * 10\%, ** 5\%. *** 1\%.

\begin{tabular}{|c|c|c|c|c|}
\hline \multirow[b]{2}{*}{ Foreign Assets } & \multicolumn{2}{|c|}{ 5-year horizon } & \multicolumn{2}{|c|}{ 10-year horizon } \\
\hline & $\begin{array}{l}0.41 \\
(0.17)\end{array}$ & $* *$ & $\begin{array}{l}0.23 \\
(0.12)\end{array}$ & $*$ \\
\hline $\mathrm{R}^{2}$ & $8 \%$ & & $7 \%$ & \\
\hline \# Observations & 408 & & 201 & \\
\hline
\end{tabular}




\section{Table A1}

The Effect of Beta and Idiosyncratic Volatility on Consumption Growth: WDI Data This table shows results for the panel regression in equation (19) in the text. The dependent variable is consumption growth over forward 5- or 10-year non-overlapping intervals, taken from WDI. The independent variables are beta and idiosyncratic volatility, both measured from year t-9 to t. The sample period is 1976-2004 and it covers 68 countries. Time- and country-fixed effects are included in all regressions. Robust standard errors clustered by country are reported in parentheses. Significance: * $10 \%$, $* * 5 \%$. *** $1 \%$.

\begin{tabular}{|c|c|c|c|c|}
\hline \multirow{5}{*}{ Idiosyncratic Volatility } & \multicolumn{2}{|c|}{ 5-year horizon } & \multicolumn{2}{|c|}{ 10-year horizon } \\
\hline & 0.31 & $* * *$ & 0.26 & $* * *$ \\
\hline & $(0.09)$ & & $(0.08)$ & \\
\hline & 0.03 & & 0.13 & \\
\hline & $(0.09)$ & & $(0.12)$ & \\
\hline $\mathrm{R}^{2}$ & $38 \%$ & & $53 \%$ & \\
\hline \# Observations & 371 & & 179 & \\
\hline
\end{tabular}




\section{Table A2}

\section{The Effect of Beta and Idiosyncratic Volatility on Consumption Growth: Different Beta and Volatility Measures}

This table shows results for the panel regression in equation (19) in the text. The dependent variable is consumption growth over forward 5- or 10-year non-overlapping intervals. The independent variables are beta and idiosyncratic volatility, both measured in one of the following ways: (1) from year t-4 to t; (2) from year t-14 to t; (3) on world GDP from year t-9 to t; (4) as averages of portfolio betas (idiosyncratic volatility) from year t-9 to t. The sample period is 1956-2000 for (1), 1966-2000 for (2), and 1961-2000 for (3) and (4). The number of countries in all regressions is 74. Time- and country-fixed effects are included in all regressions. Robust standard errors clustered by country are reported in parentheses. Significance: * $10 \%$, ** 5\%. *** $1 \%$.

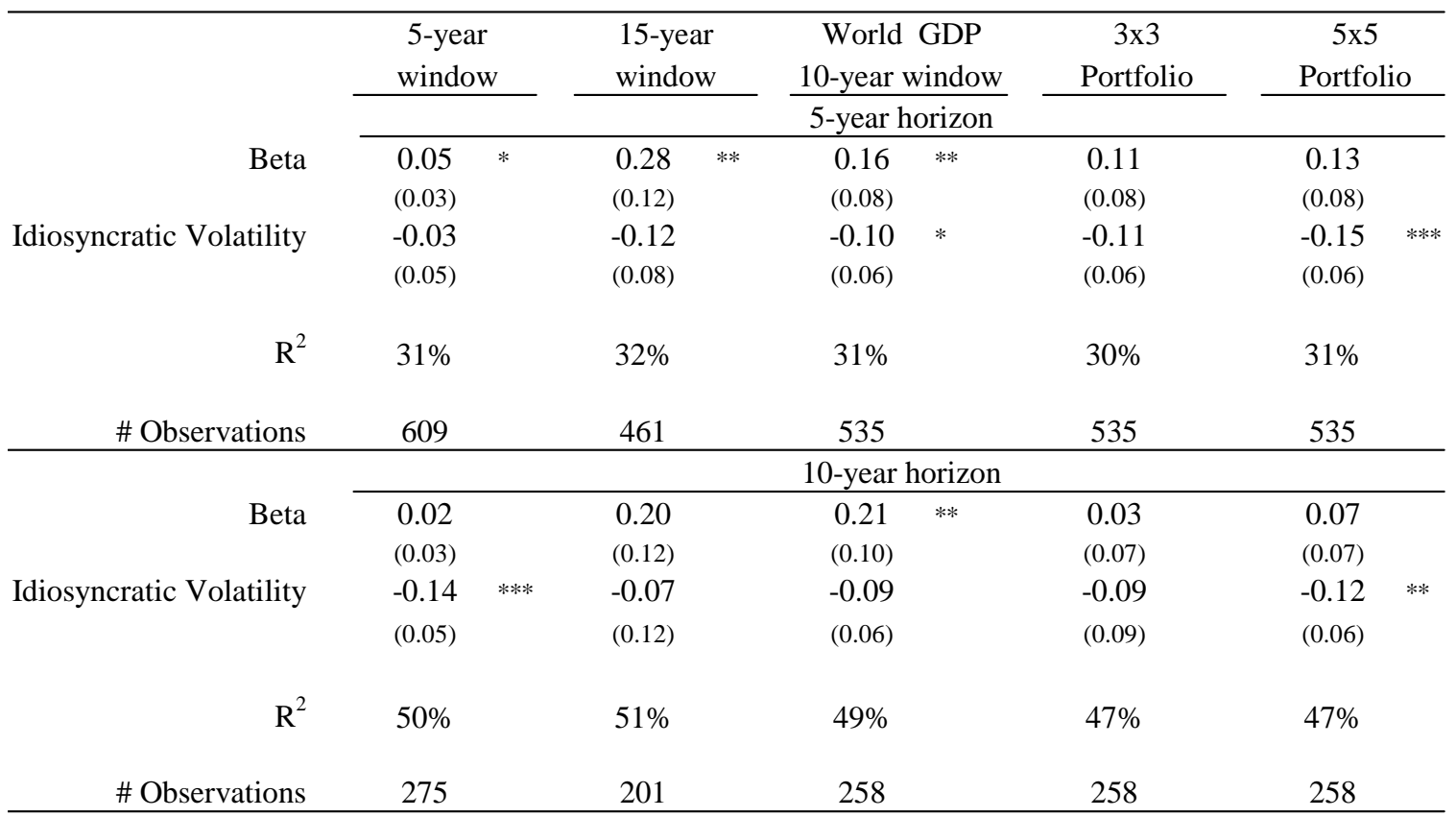


Table A3

The Effect of Beta and Idiosyncratic Volatility on Consumption Growth: Additional Determinants of Growth

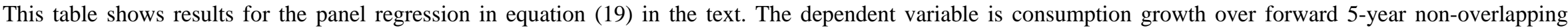

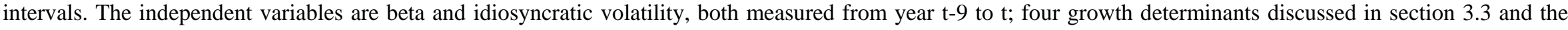

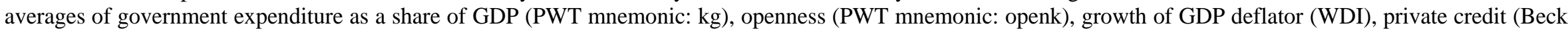



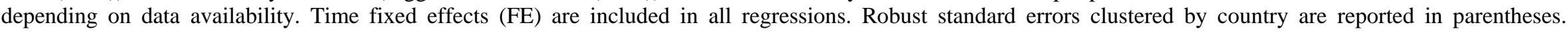
Significance: * 10\%, ** 5\%. *** 1\%.

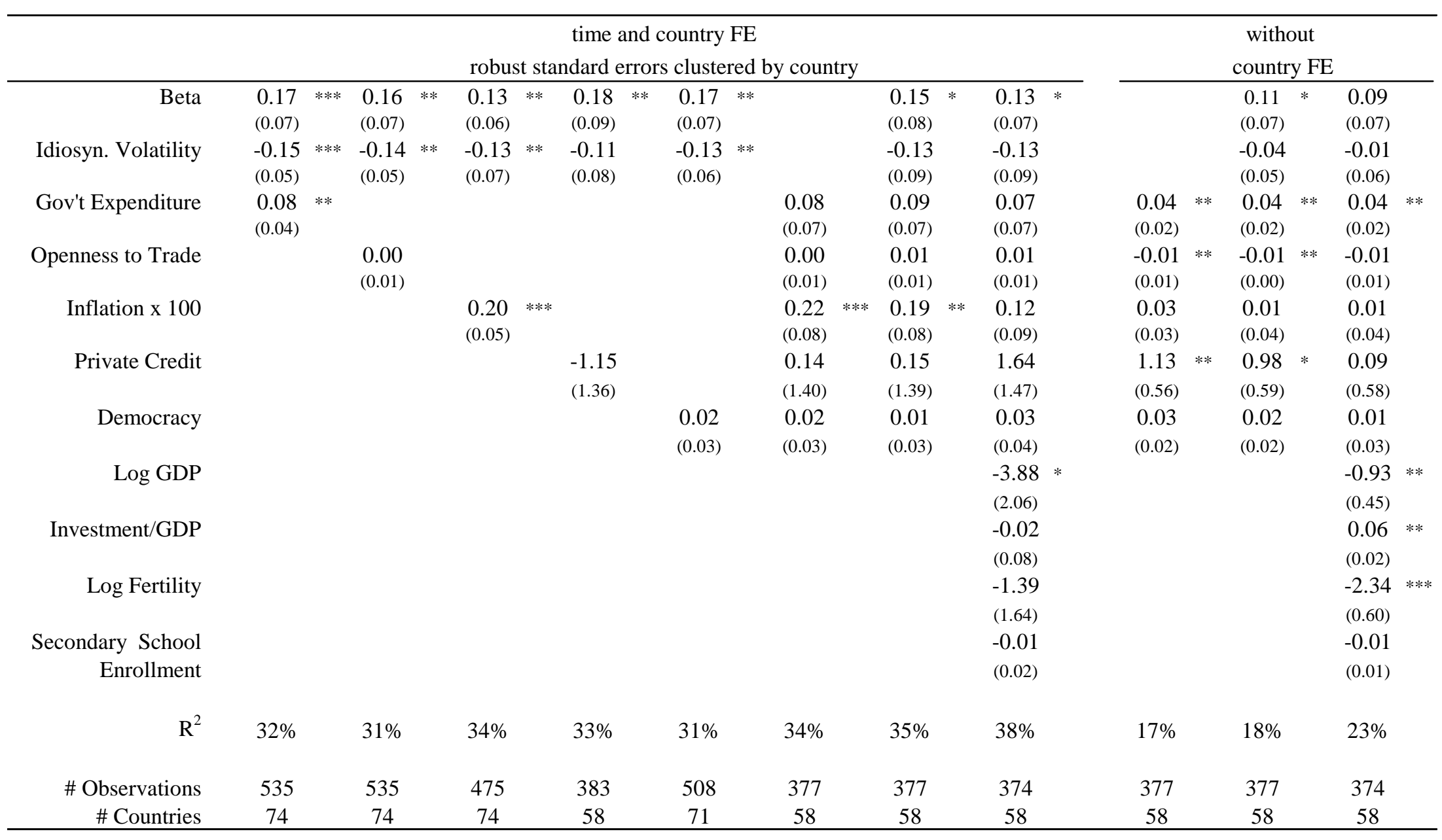




\section{Table A4}

\section{Averages of Private and Public External Debt Across Portfolios Sorted by Beta and}

Idiosyncratic Volatility

Each year $t=\{1970,1975, \ldots, 1995\}$, countries are assigned to one of three portfolios based on tercile breakpoints of the distribution of betas (idiosyncratic volatilities). Tercile breakpoints are obtained separately (i.e. not one within the other) from the cross-section of betas and idiosyncratic volatilities every year t. For each portfolio, we compute the mean of external private and public debt (from WDI) measured in year $\mathrm{t}$.

\begin{tabular}{|c|c|c|c|}
\hline \multirow[b]{3}{*}{ Beta Portfolios } & \multicolumn{3}{|c|}{ Idiosyncratic Volatility Portfolios } \\
\hline & Low & Medium & High \\
\hline & \multicolumn{3}{|c|}{ Private Debt (\% GDP) } \\
\hline$\overline{\text { Low }}$ & 3 & 4 & 4 \\
\hline Medium & 3 & 3 & 3 \\
\hline \multirow[t]{2}{*}{ High } & 4 & 5 & 5 \\
\hline & \multicolumn{3}{|c|}{ Public Debt (\% GDP) } \\
\hline Low & 52 & 36 & 34 \\
\hline Medium & 22 & 34 & 36 \\
\hline High & 23 & 38 & 72 \\
\hline
\end{tabular}


Table A5

Correlation Matrix for All Independent Variables

\begin{tabular}{|c|c|c|c|c|c|c|c|c|c|c|c|c|c|c|}
\hline & Beta & $\begin{array}{c}\text { Idios. } \\
\text { Volatility }\end{array}$ & Log GDP & I/GDP & $\begin{array}{c}\text { Log } \\
\text { Fertility }\end{array}$ & $\begin{array}{c}\text { Sec. Sch. } \\
\text { Enrol. }\end{array}$ & $\begin{array}{c}\text { Gov't } \\
\text { Exp/GDP }\end{array}$ & Openness & Inflation & $\begin{array}{l}\text { Private } \\
\text { Credit }\end{array}$ & Democr. & $\begin{array}{c}\text { Foreign } \\
\text { Assets }\end{array}$ & $\begin{array}{c}\text { Foreign } \\
\text { Liab. }\end{array}$ & $\begin{array}{l}\text { Net Ext. } \\
\text { Position }\end{array}$ \\
\hline Beta & 1.00 & & & & & & & & & & & & & \\
\hline Idios. Volatility & 0.06 & 1.00 & & & & & & & & & & & & \\
\hline Log GDP & 0.05 & -0.41 & 1.00 & & & & & & & & & & & \\
\hline I/GDP & -0.04 & -0.29 & 0.68 & 1.00 & & & & & & & & & & \\
\hline Log Fertility & -0.11 & 0.39 & -0.88 & -0.62 & 1.00 & & & & & & & & & \\
\hline Sec. Sch. Enrol. & 0.07 & -0.31 & 0.77 & 0.53 & -0.77 & 1.00 & & & & & & & & \\
\hline Gov't Ex/GDP & 0.08 & 0.35 & -0.30 & -0.25 & 0.30 & -0.20 & 1.00 & & & & & & & \\
\hline Openness & -0.02 & 0.32 & -0.26 & -0.14 & 0.24 & -0.11 & 0.24 & 1.00 & & & & & & \\
\hline Inflation & 0.27 & 0.21 & -0.12 & -0.14 & 0.07 & -0.09 & 0.27 & -0.08 & 1.00 & & & & & \\
\hline Private Credit & 0.03 & -0.34 & 0.70 & 0.55 & -0.68 & 0.67 & -0.32 & -0.12 & -0.15 & 1.00 & & & & \\
\hline Democracy & 0.03 & -0.29 & 0.50 & 0.30 & -0.51 & 0.50 & -0.12 & -0.08 & 0.01 & 0.34 & 1.00 & & & \\
\hline Foreign Assets & 0.06 & -0.17 & 0.51 & 0.24 & -0.52 & 0.47 & -0.14 & 0.21 & -0.04 & 0.52 & 0.31 & 1.00 & & \\
\hline Foreign Liab. & 0.28 & 0.16 & 0.04 & -0.10 & -0.11 & 0.09 & 0.25 & 0.27 & 0.51 & 0.07 & 0.12 & 0.47 & 1.00 & \\
\hline Net Ext. Position & -0.25 & -0.31 & 0.36 & 0.31 & -0.29 & 0.27 & -0.39 & -0.13 & -0.59 & 0.34 & 0.12 & 0.28 & -0.71 & 1.00 \\
\hline
\end{tabular}


Table A6

Transition Matrices for Beta and Idiosyncratic Volatility Portfolios

\begin{tabular}{cccccc}
\hline \multicolumn{5}{c}{ Beta Portfolios } \\
\hline & 1 & 2 & 3 & 4 & 5 \\
\cline { 2 - 6 } 2 & 46 & 24 & 10 & 12 & 9 \\
3 & 19 & 20 & 27 & 19 & 15 \\
4 & 8 & 27 & 22 & 23 & 11 \\
5 & 10 & 20 & 29 & 24 & 20 \\
\hline \multicolumn{5}{c}{ Idiosyncratic Volatility Porfolios } \\
\hline 1 & 67 & 2 & 3 & 4 & 5 \\
2 & 27 & 40 & 6 & 5 & 1 \\
3 & 5 & 30 & 38 & 8 & 6 \\
4 & 3 & 6 & 31 & 37 & 8 \\
5 & 1 & 4 & 7 & 24 & 64 \\
\hline
\end{tabular}


Table A7

List of Countries in the PWT Sample and Average Beta

\begin{tabular}{|c|c|c|c|}
\hline Country & Beta & Country & Beta \\
\hline Argentina & 0.60 & Japan & 0.87 \\
\hline Australia & 0.41 & Jordan & -2.01 \\
\hline Austria & 1.79 & Kenya & 1.59 \\
\hline Bangladesh & -2.63 & Korea & 1.33 \\
\hline Belgium & 0.87 & Luxembourg & 0.77 \\
\hline Bolivia & -0.38 & Malaysia & 1.00 \\
\hline Brazil & 0.12 & Mexico & 0.78 \\
\hline Cameroon & -1.91 & Morocco & -0.15 \\
\hline Canada & 1.30 & Netherlands & 1.05 \\
\hline Chile & 2.74 & New Zealand & 1.20 \\
\hline China & 0.62 & Nicaragua & 3.79 \\
\hline Colombia & 0.85 & Norway & 0.57 \\
\hline Costa Rica & 1.60 & Pakistan & -0.65 \\
\hline Cote d'Ivoire & 1.50 & Paraguay & 0.72 \\
\hline Denmark & 2.55 & Peru & -0.52 \\
\hline Dominican Republic & 1.60 & Philippines & 0.76 \\
\hline Ecuador & 0.18 & Poland & 2.99 \\
\hline Egypt & 1.52 & Portugal & 0.75 \\
\hline El Salvador & 1.91 & Romania & 2.20 \\
\hline Finland & 1.13 & Senegal & -1.05 \\
\hline France & 1.08 & Sierra Leone & 0.75 \\
\hline Germany & 0.39 & Singapore & 3.85 \\
\hline Ghana & 1.37 & South Africa & 0.31 \\
\hline Greece & 0.53 & Spain & 0.55 \\
\hline Guatemala & 0.54 & Sri Lanka & 1.28 \\
\hline Guinea & 0.07 & Sweden & 0.12 \\
\hline Honduras & 1.26 & Switzerland & 0.69 \\
\hline Hong Kong & 1.74 & Syria & 1.94 \\
\hline Hungary & -0.39 & Thailand & 0.62 \\
\hline Iceland & 0.01 & Tunisia & 0.14 \\
\hline India & 0.75 & Turkey & 1.19 \\
\hline Indonesia & -3.50 & United Kingdom & 0.95 \\
\hline Iran & -1.13 & United States & 1.40 \\
\hline Ireland & 1.65 & Uruguay & 1.00 \\
\hline Israel & 0.35 & Venezuela & 0.40 \\
\hline Italy & 1.79 & Zambia & 1.70 \\
\hline Jamaica & -0.58 & Zimbabwe & -0.36 \\
\hline
\end{tabular}



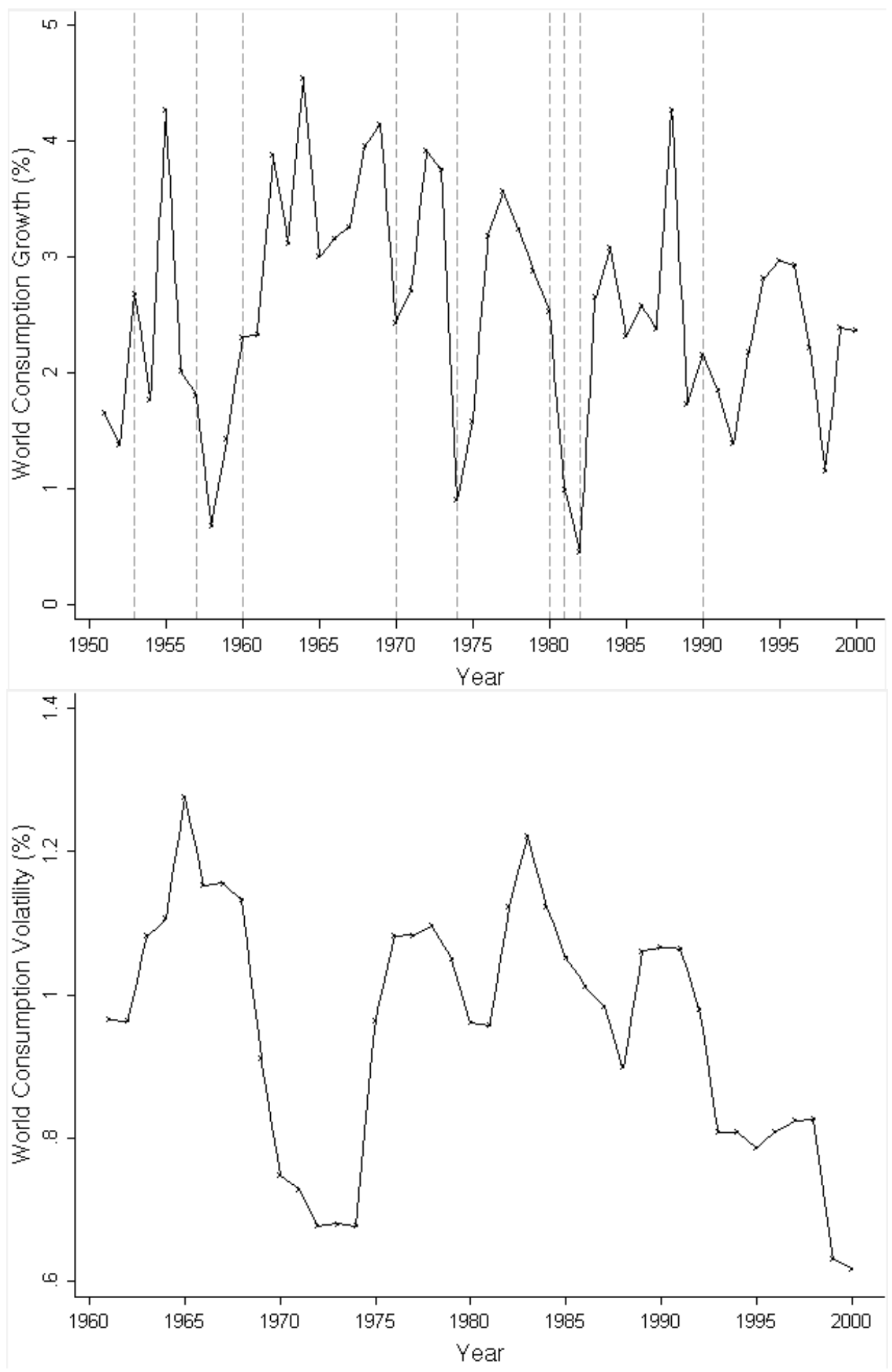

Figure 1. World Consumption Growth and World Consumption Volatility. World consumption growth is calculated as the total-consumption-weighted average of national per capita consumption growth rates. World consumption growth volatility is the standard deviation of world consumption growth computed with a backwards 10 -year moving window. The dashed lines in the top figure represent NBER recessions in the U.S. 

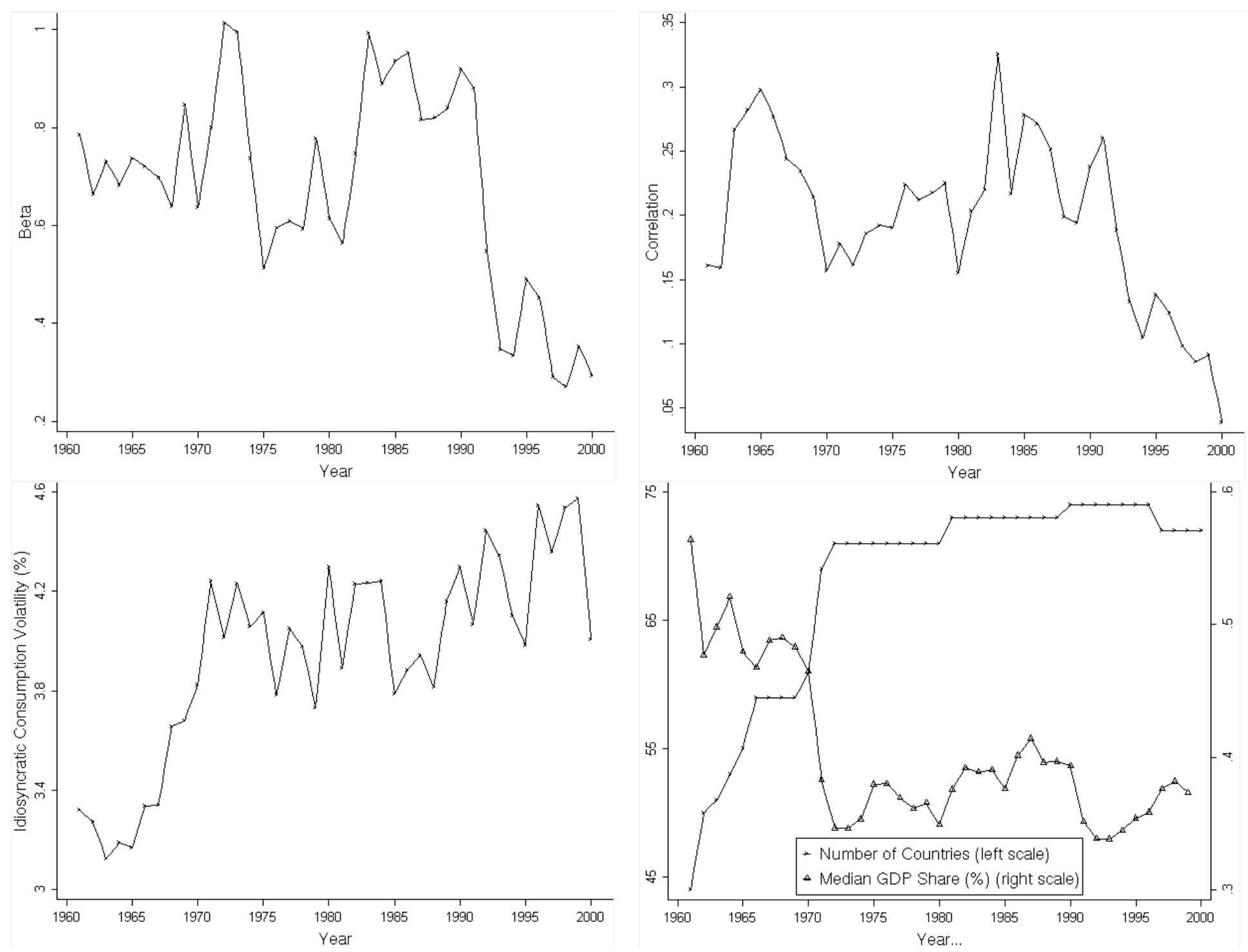

Figure 2. Median Beta, Correlation, Idiosyncratic Consumption Volatility, GDP Share and Number of Countries. Beta is the regression coefficient of a country's consumption growth on world consumption growth estimated with a backwards 10 -year moving window. Idiosyncratic volatility is defined as the standard deviation of residuals from that regression. The correlation is between a country's consumption growth and world consumption growth over the same window. GDP share is total GDP of a country over world GDP. For beta, volatility, correlation and GDP share the figure shows the sample median (across countries) in each year. The number of countries corresponds to the countries in the Penn World Table each year after imposing the restrictions described in section 2.1. 


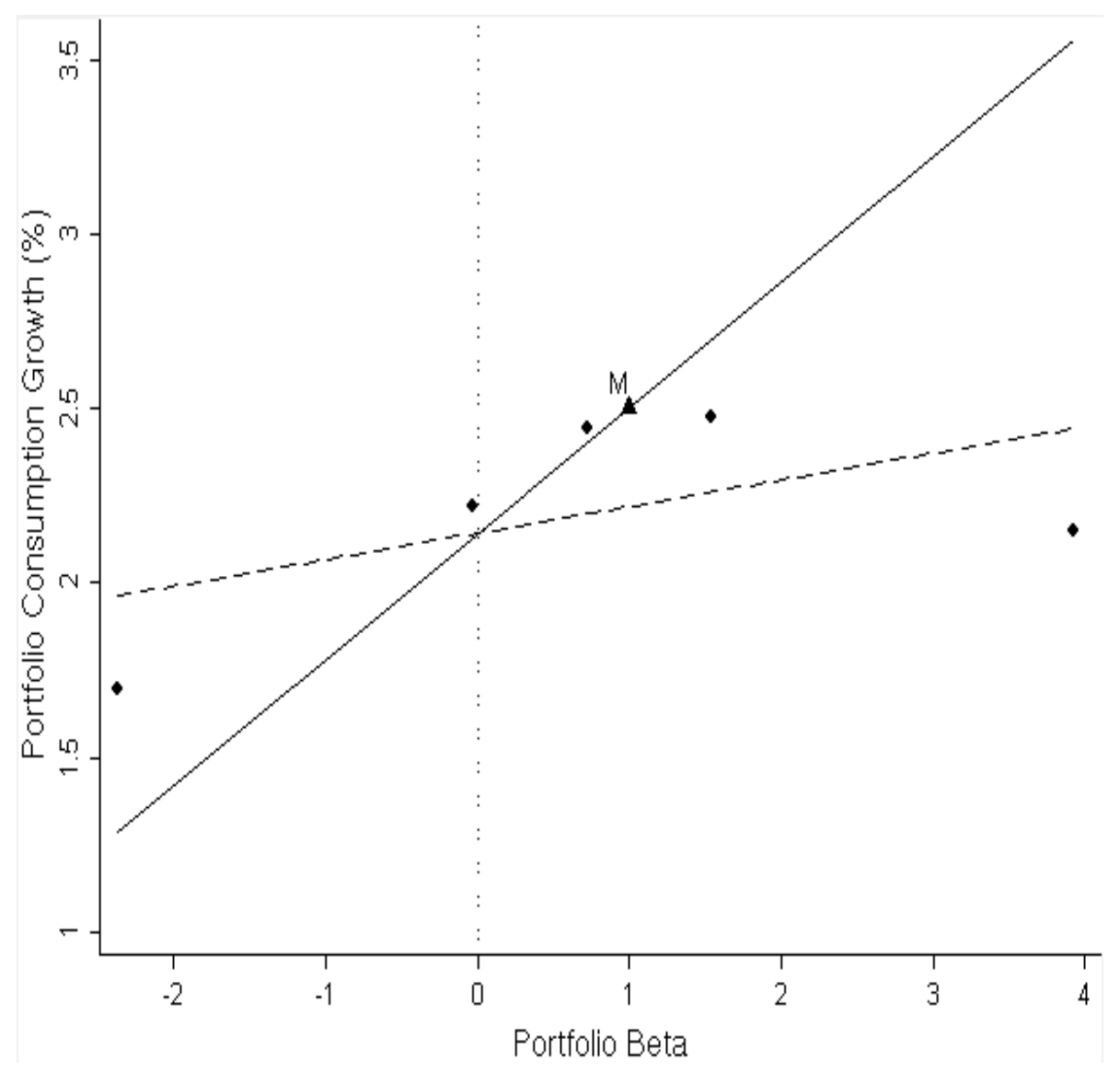

Figure 3. Consumption Growth Versus Beta for 5 Beta Portfolios. The figure shows the average beta and average consumption growth for 5 country portfolios based on beta. Every year $t=\{1960,1965$, $1970, \ldots, 1995\}$, countries are assigned to portfolios based on quintile breakpoints that are computed that year based on the cross-section of betas. For each country we compute the consumption growth over 5-year non-overlapping intervals $t+1$ to $t+5$ (specifically, 1961-1965, 1966-1970,.., 1996-2000), and we then average over countries in each portfolio. Beta is measured from year t-9 to t. The dashed line is the fitted OLS line using the 5 portfolio observations. The point M represents the world ("market") portfolio, which by definition has a beta equal to 1 . The solid line goes through point $\mathrm{M}$ and the zero-beta portfolio growth implied by the previous OLS line. 




Figure 4. Beta and Idiosyncratic Volatility. Beta is the regression coefficient of a country's consumption growth on world consumption growth estimated with a backwards 10-year moving window. Idiosyncratic volatility is defined as the standard deviation of residuals from that regression. This figure shows betas and volatilities at 5-year intervals in our sample of 74 countries (535 observations in total). The solid line corresponds to the fitted values from a regression of volatility on beta and its quadratic term. 

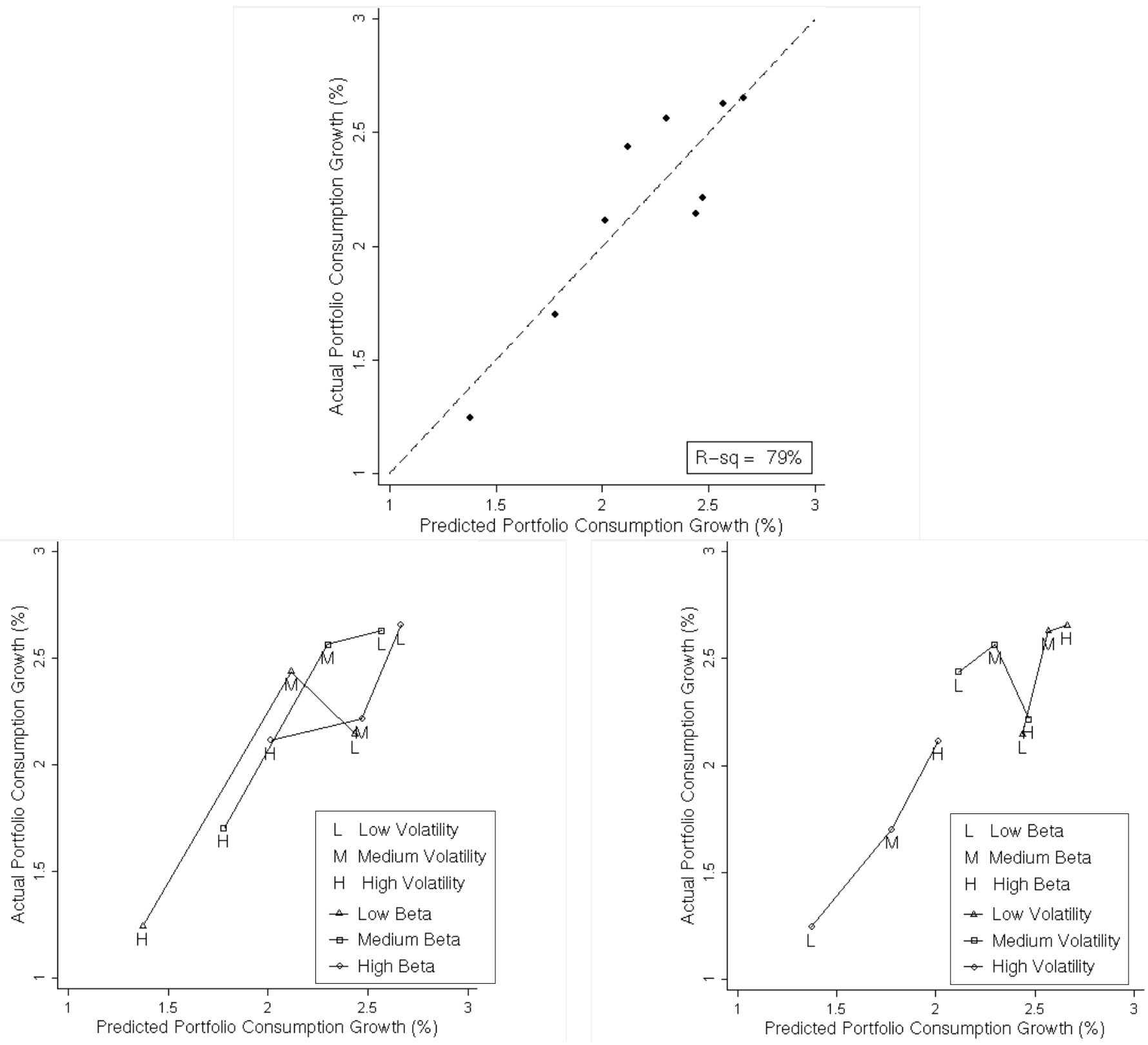

Figure 5. Actual Versus Predicted Consumption Growth for 9 Portfolios Sorted by Beta and Idiosyncratic Volatility. Predicted consumption growth is the fitted value from a regression of portfolio average consumption growth on portfolio average beta and idiosyncratic volatility using the 9 portfolio observations. In the top figure, the dashed line is the 45 degree line. $\mathrm{R}^{2}$ of the fit is also reported. In the left (right) bottom figure, points are connected within beta (idiosyncratic volatility) portfolios and labeled as L(low)-M(median)-H(high) based on their ranking in idiosyncratic volatility (beta). Each year $t=\{1960,1965,1970, \ldots, 1995\}$ countries are assigned to one of nine portfolios based on how their beta and idiosyncratic volatility compare to the tercile breakpoints in the cross-section of betas and idiosyncratic volatility. In each portfolio we compute averages of the following variables: (1) consumption growth over 5-year non-overlapping intervals $t+1$ to $t+5$, (2) beta and (3) idiosyncratic volatility, both measured from year t-9 to t. 

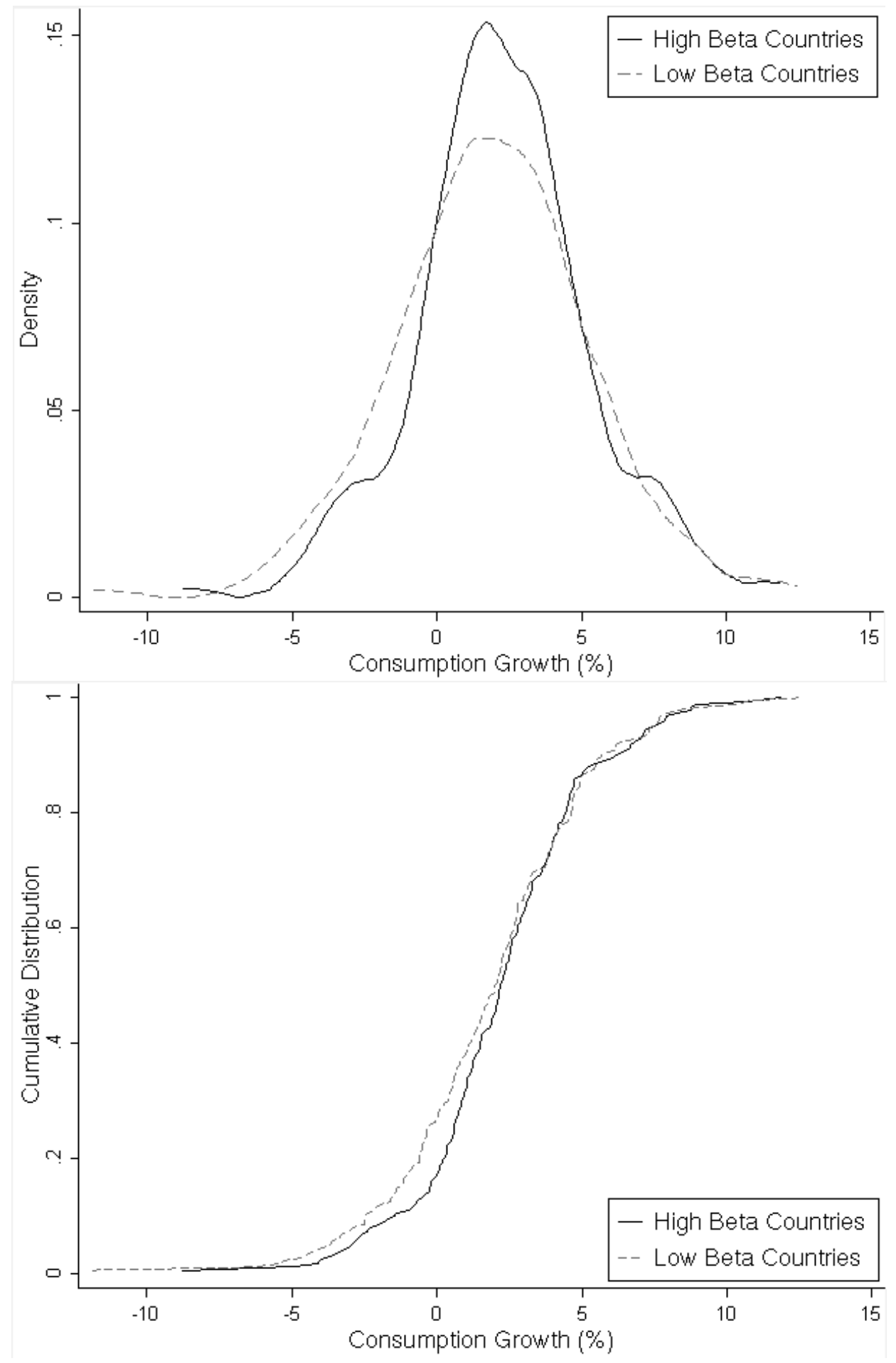

Figure 6.1. Distribution of Consumption Growth in High and Low Beta Countries. Countries are assigned to portfolios based on tercile breakpoints that are computed every year $t$ in the cross-section of betas, where $t=\{1960,1965,1970, \ldots, 1995\}$. Beta is measured from year $t-9$ to $t$. The top figure shows the fitted density function and the bottom figure shows the cumulative distribution function of consumption growth for countries in the top ( $3^{\text {rd }}$ tercile) and bottom $\left(1^{\text {st }}\right.$ tercile) portfolios formed on beta. Consumption growth is computed over 5-year non-overlapping intervals $t+1$ to $t+5$. 

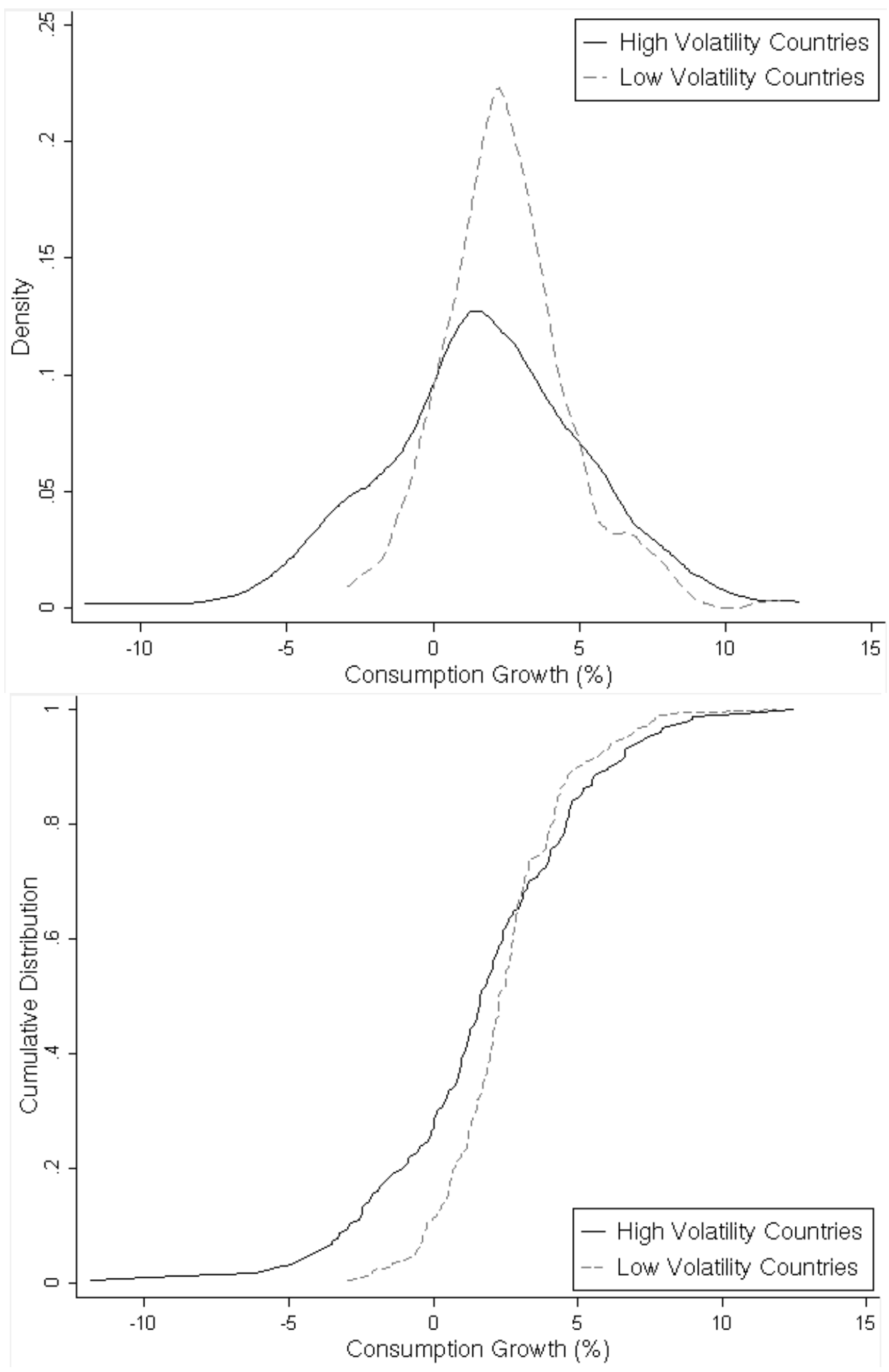

Figure 6.2. Distribution of Consumption Growth in High and Low Volatility Countries. Countries are assigned to portfolios based on tercile breakpoints that are computed every year $t$ in the cross-section of idiosyncratic volatilities, where $t=\{1960,1965,1970, \ldots, 1995\}$. Idiosyncratic volatility is measured from year t-9 to t. The top figure shows the fitted density function and the bottom figure shows the cumulative distribution function of consumption growth for countries in the top ( $3^{\text {rd }}$ tercile) and bottom ( $1^{\text {st }}$ tercile) portfolios formed on idiosyncratic voaltility. Consumption growth is computed over 5-year nonoverlapping intervals $\mathrm{t}+1$ to $\mathrm{t}+5$. 

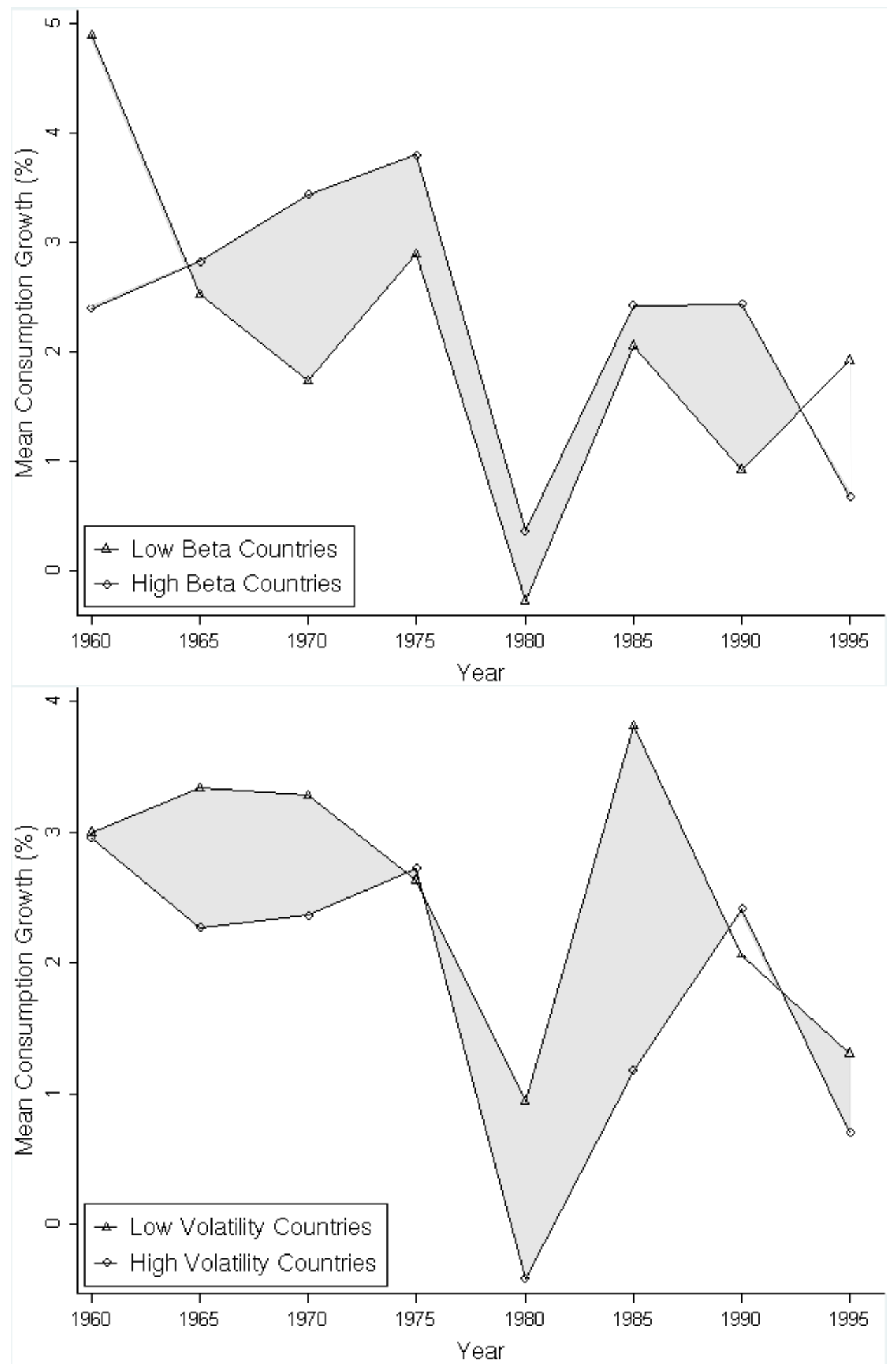

Figure 7. Consumption Growth Spread Between High and Low Beta Countries (Top Figure), and High and Low Idiosyncratic Volatility Countries (Bottom Figure). The spread is colored gray when the average consumption growth for high beta (idiosyncratic volatility) countries is greater (lower) than that for low beta (idiosyncratic volatility) countries. Countries are assigned to portfolios based on tercile breakpoints that are computed every year $\mathrm{t}$ in the cross-section of betas (idiosyncratic volatilities), where $\mathrm{t}$ $=\{1960,1965,1970, \ldots, 1995\}$. Beta (idiosyncratic volatility) is measured from year t-9 to t. "High" portfolios include countries in the $3^{\text {rd }}$ tercile and "low" portfolios include countries in the $1^{\text {st }}$ tercile of the distribution of betas (idiosyncratic volatility) in year t. Consumption growth is computed over the 5-year interval $t+1$ to $t+5$ that follows each $t$. 

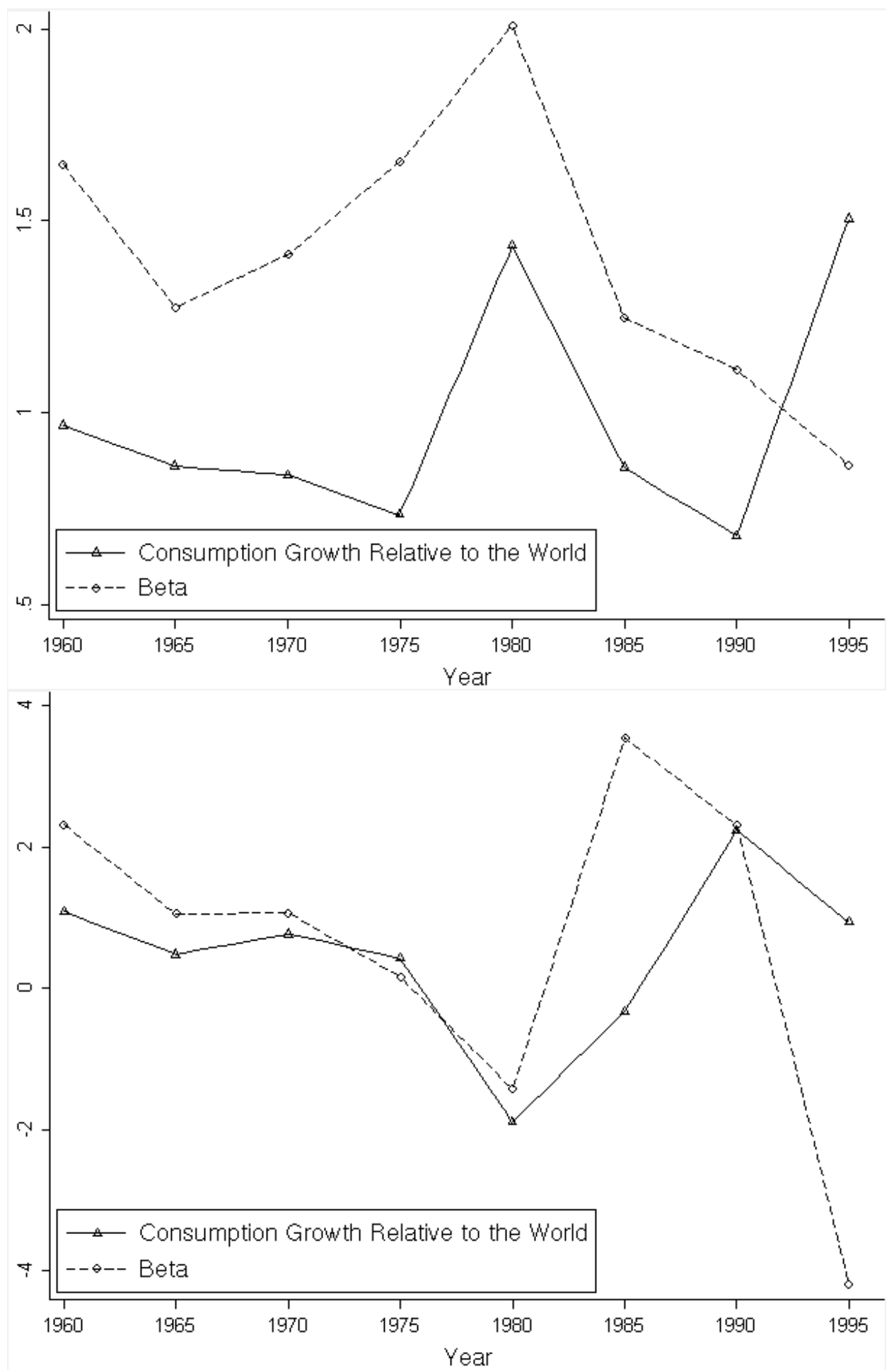

Figure 8. Time-Series of Beta and Consumption Growth Relative to the World for the U.S. (Top Figure) and Argentina (Bottom Figure). Every year $t=\{1960,1965,1970, \ldots, 1995\}$, we compute annualized consumption growth over the following 5-year interval t+1 to t+5 (specifically, 1961-1965, $1966-1970, \ldots, 1996-2000$ ) and divide it by world consumption growth over the same time interval. Beta is estimated using data from year t-9 to $t$ for each country. 

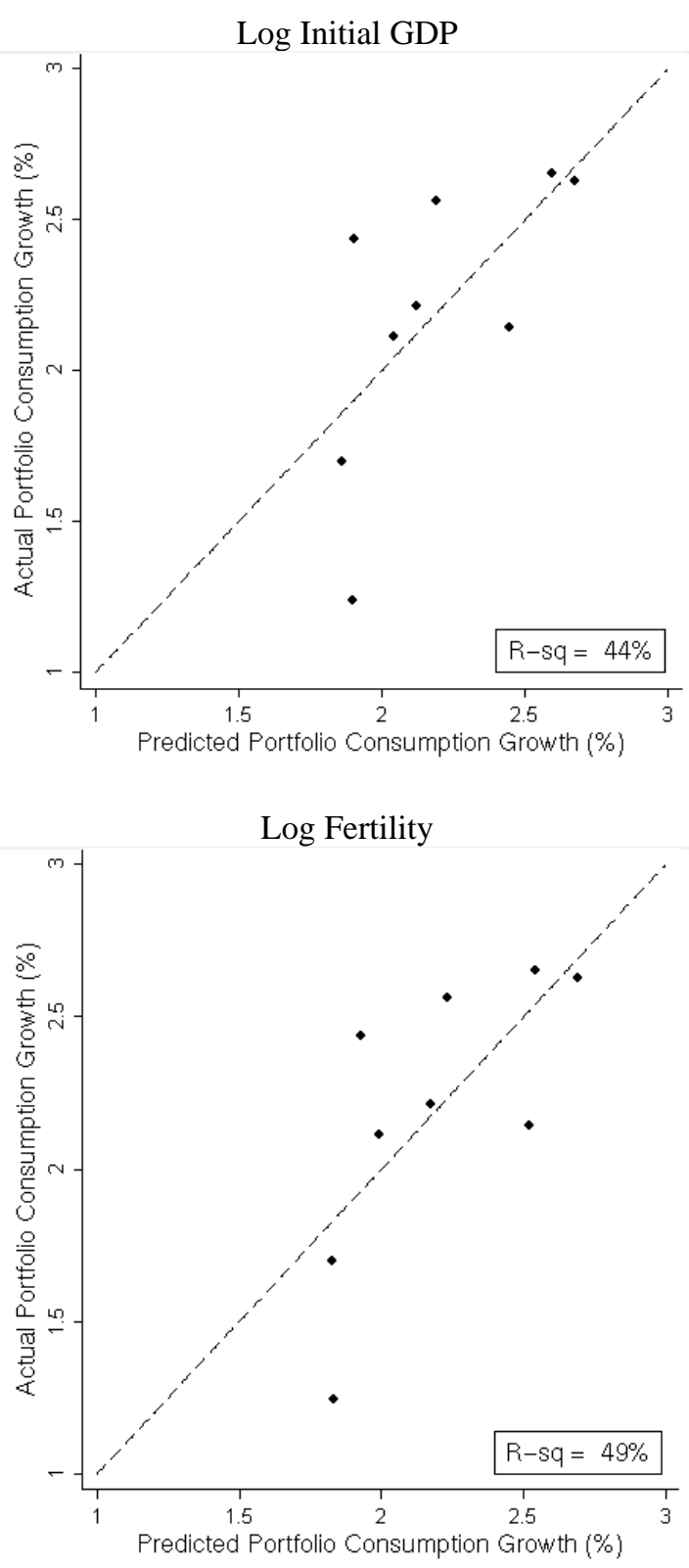
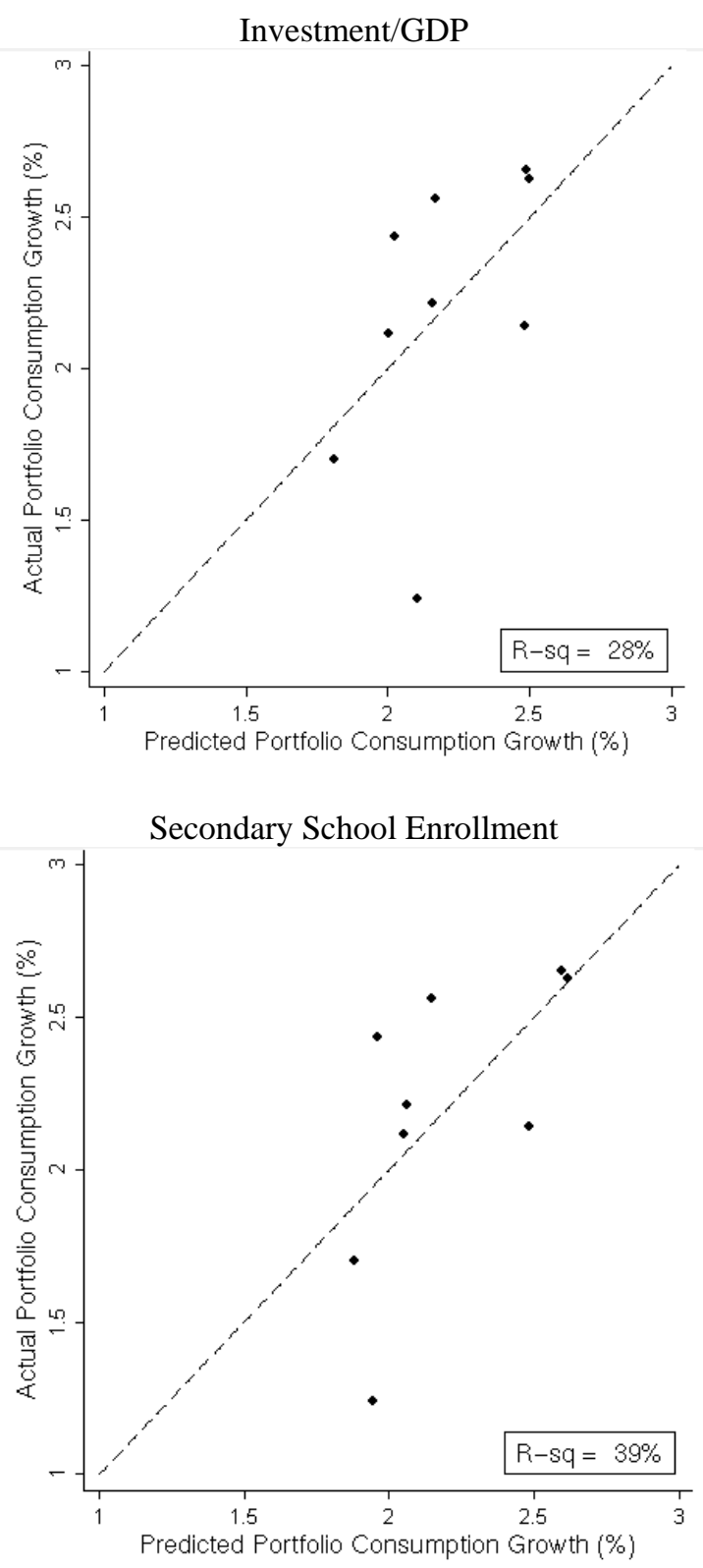

Figure 9.1. Actual Versus Predicted Consumption Growth for 9 Portfolios Sorted by Beta and Idiosyncratic Volatility. Predicted consumption growth is the fitted value from a regression of portfolio average consumption growth on portfolio averages of the variables in the headings of each panel. The dashed line is the 45 degree line. $\mathrm{R}^{2}$ of the fit is also reported. The sorting procedure is as follows. Each year $t=\{1960,1965$, $1970, \ldots, 1995\}$ countries are assigned to one of nine portfolios based on how their beta and idiosyncratic volatility compare to the tercile breakpoints in the cross-section of betas and idiosyncratic volatility. In each portfolio we compute averages of the following variables: (1) consumption growth over 5-year non-overlapping intervals $t+1$ to $t+5$; (2) beta and idiosyncratic volatility, both measured from year $t-9$ to $t$; (3) log initial GDP measured in year t; (3) investment/GDP and (4) log fertility, both averaged over the period t-9 to t; and (5) secondary school enrollment measured in year $t$. 
Log Initial GDP, Investment/GDP, Log Fertility, Secondary School Enrollment

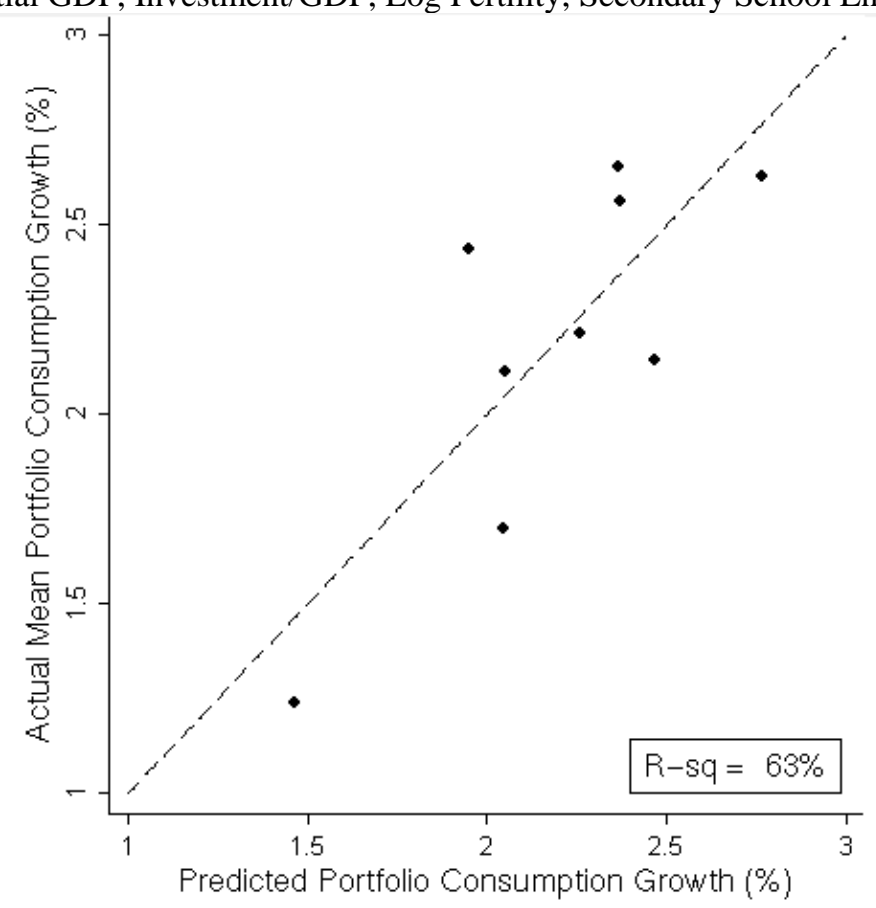

Beta, Idiosyncratic Volatility

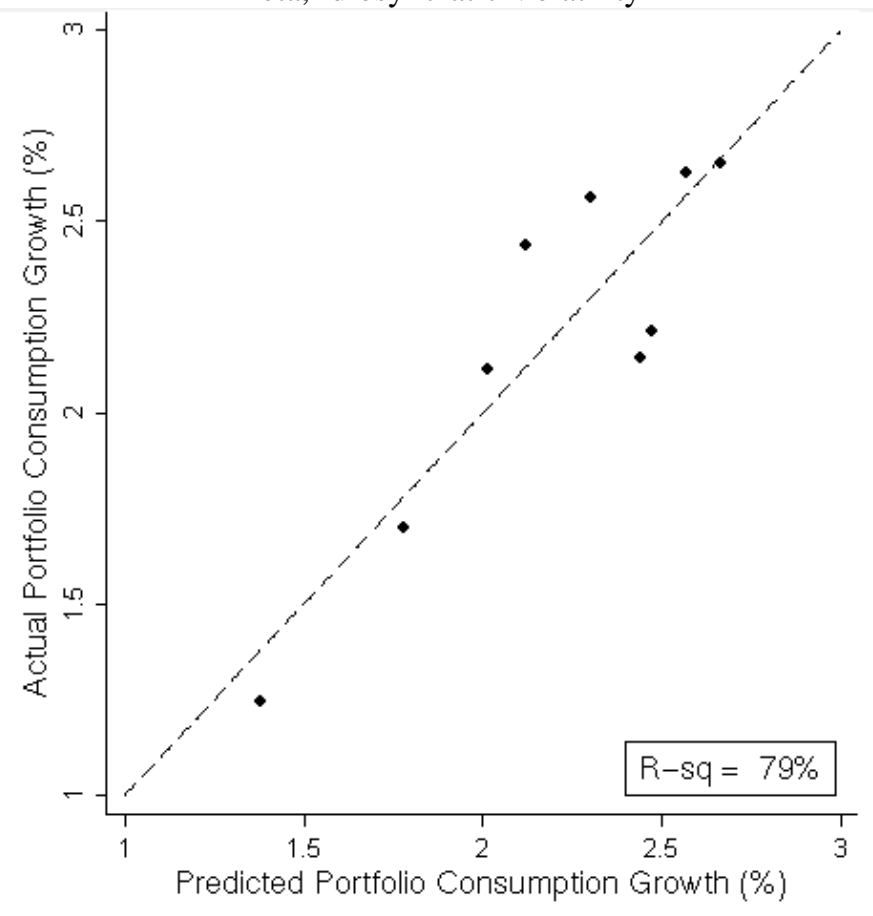

Figure 9.2. Actual Versus Predicted Mean Consumption Growth for 9 Portfolios Sorted by Beta and Idiosyncratic Volatility. See notes to figure 8.1. The top panel uses all 4 predictor variables used in table 8.1. The lower panel uses beta and idiosyncratic volatility to predict consumption growth. 

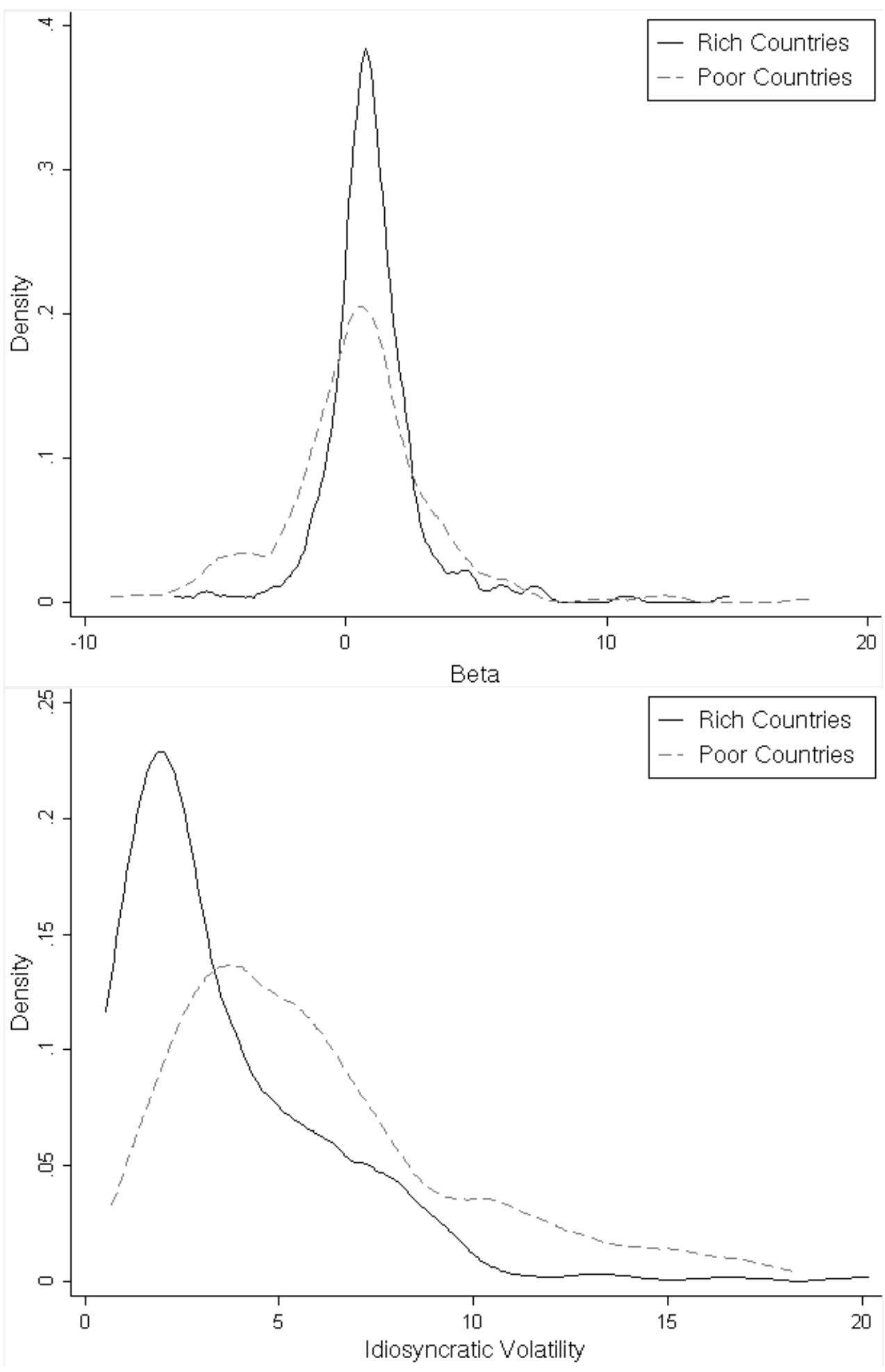

Figure 10. Distributions of Beta (Top Figure) and Idiosyncratic Volatility (Bottom Figure) for Poor and Rich Countries. Countries are grouped as "rich" or "poor" based on their real per capita GDP in year 1990 when compared to the sample median of GDP in 1990. Beta represents the regression coefficient of a country's consumption growth on world consumption growth computed every year with a backwards 10year moving window. Idiosyncratic volatility is the standard deviation of residuals from the same regression. 

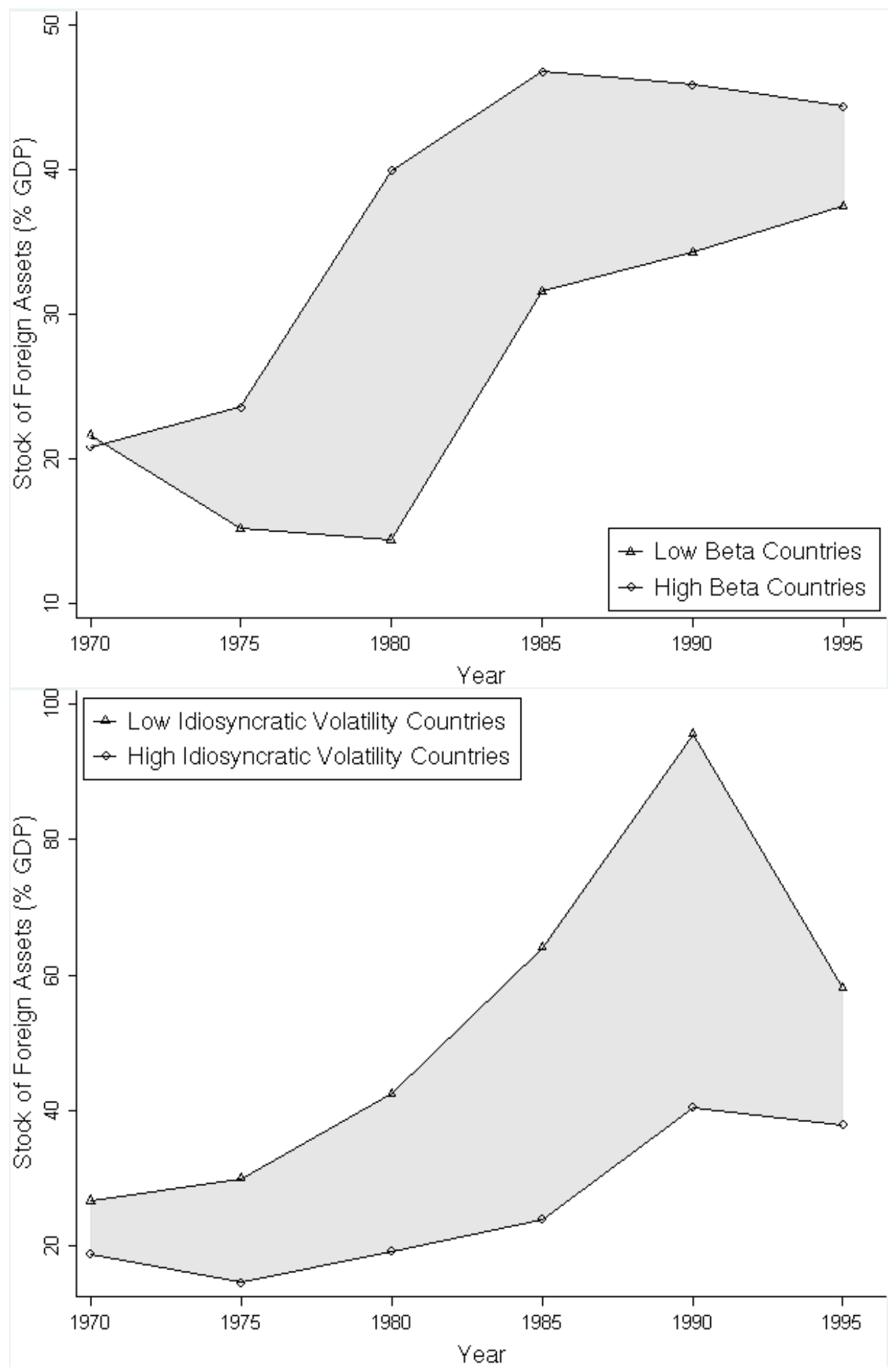

Figure 11. Spread in the Stock of Foreign Assets Between High and Low Beta (Volatility) Countries. The upper (lower) panel shows the difference in foreign assets between countries with high (3rd tercile) and low ( $1^{\text {st }}$ tercile) betas (idiosyncratic volatilities). Countries are assigned to portfolios based on tercile breakpoints that are computed every year $\mathrm{t}$ for the cross-section of betas (idiosyncratic volatilities), where $\mathrm{t}$ $=\{1960,1965,1970, \ldots, 1995\}$. For countries in each portfolio, we compute the average of the stock of foreign assets over GDP measured in year t. Beta and volatility are measured from year t-9 to t. Data on foreign assets is from Lane and Milesi-Ferretti (2001). 


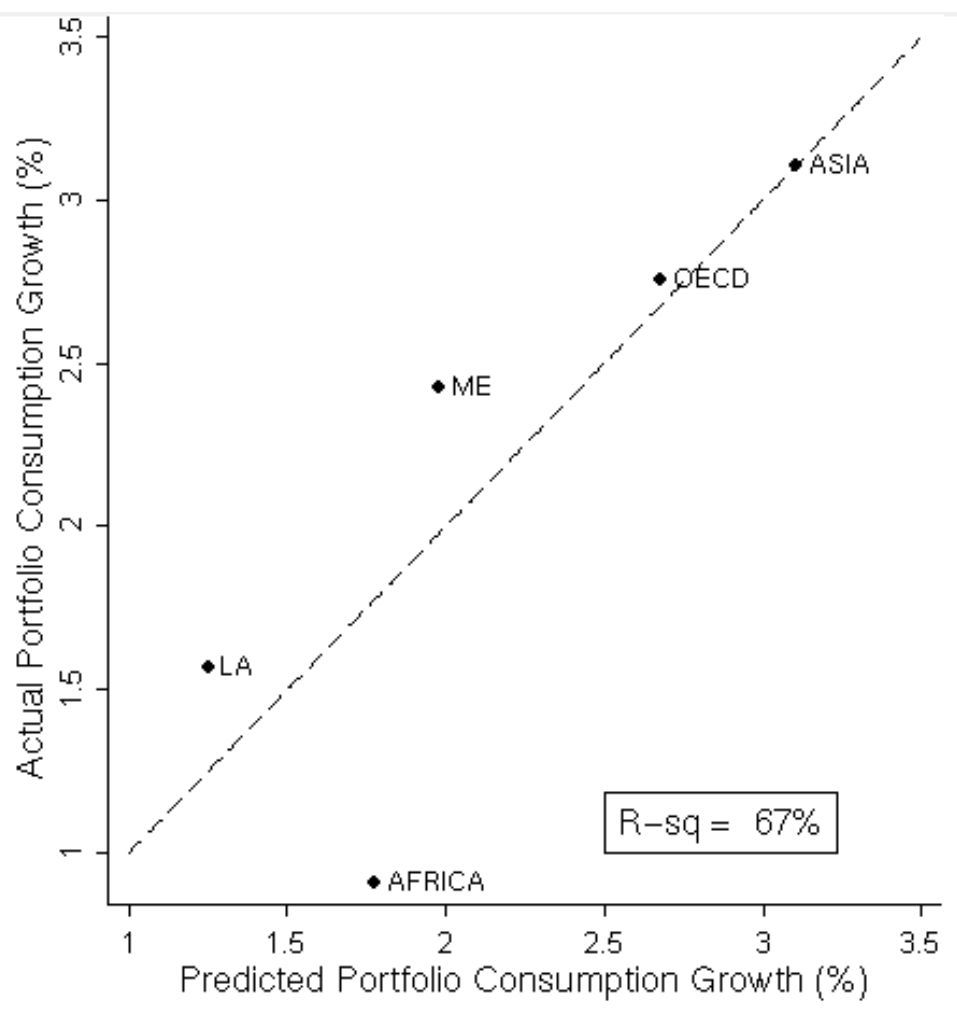

Figure A1. Actual Versus Predicted Consumption Growth for 5 Portfolios Formed on Geographical Regions. Predicted consumption growth is the fitted value from a regression of portfolio average consumption growth on portfolio average beta and idiosyncratic volatility using the five portfolio observations. The dashed line is the 45 degree line. $\mathrm{R}^{2}$ of the fit is also reported. Countries are assigned to one of five portfolios based on their geographical location. In each portfolio we compute averages of the following variables: (1) consumption growth over 5-year non-overlapping intervals $t+1$ to $t+5$, (2) beta and (3) idiosyncratic volatility, both measured from year t-9 to t. 

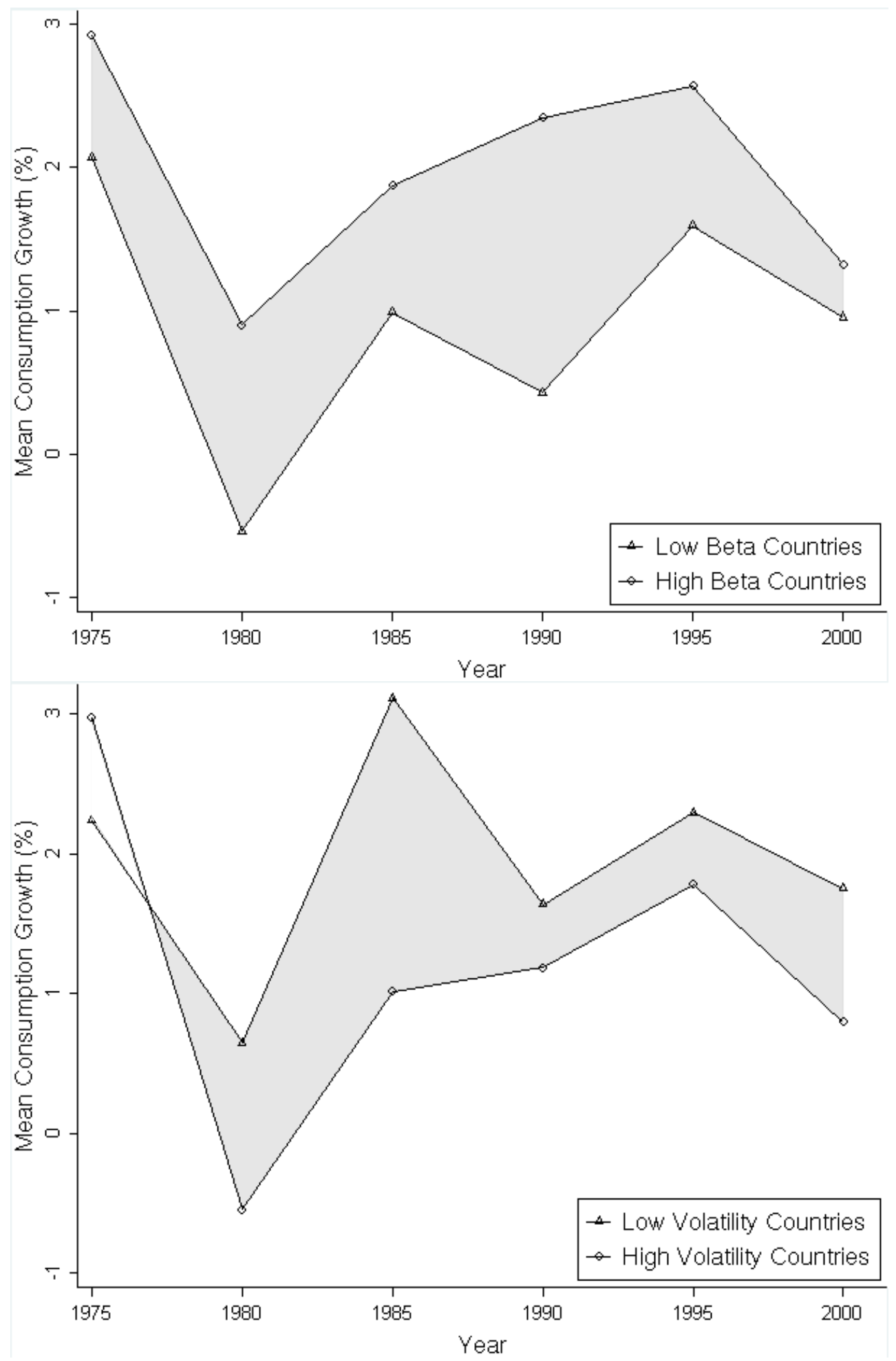

Figure A2. Consumption Growth Spread Between High and Low Beta Countries (Top Figure), and High and Low Idiosyncratic Volatility Countries (Bottom Figure): WDI sample. The spread is colored gray when the average consumption growth for high beta (idiosyncratic volatility) countries is greater (lower) than that for low beta (idiosyncratic volatility) countries. Countries are assigned to portfolios based on tercile breakpoints that are computed every year $t$ in the cross-section of betas (idiosyncratic volatilities), where $t=\{1975,1980$, $1985, \ldots, 2000\}$. Beta (idiosyncratic volatility) is measured from year t-9 to t. "High" portfolios include countries in the $3^{\text {rd }}$ tercile and "low" portfolios include countries in the $1^{\text {st }}$ tercile of the distribution of betas (idiosyncratic volatility) in year t. Consumption growth is computed over the 5 -year interval $t+1$ to $t+5$ that follows each t. 